LA W RENCE LIVERMORE NAT IO N A L LABORATORY

COAMPS Application to Global and Homeland Security Threat Problems

Hung-Neng (Steve) Chin, Lee G. Glascoe

September 16, 2004 
This document was prepared as an account of work sponsored by an agency of the United States Government. Neither the United States Government nor the University of California nor any of their employees, makes any warranty, express or implied, or assumes any legal liability or responsibility for the accuracy, completeness, or usefulness of any information, apparatus, product, or process disclosed, or represents that its use would not infringe privately owned rights. Reference herein to any specific commercial product, process, or service by trade name, trademark, manufacturer, or otherwise, does not necessarily constitute or imply its endorsement, recommendation, or favoring by the United States Government or the University of California. The views and opinions of authors expressed herein do not necessarily state or reflect those of the United States Government or the University of California, and shall not be used for advertising or product endorsement purposes.

This work was performed under the auspices of the U.S. Department of Energy by University of California, Lawrence Livermore National Laboratory under Contract W-7405-Eng-48. 
UCRL-TR-206584

\title{
COAMPS Application to Global and Homeland Security Threat Problems
}

\author{
Hung-Neng S. Chin, and Lee G. Glascoe \\ Atmospheric Science Division \\ Lawrence Livermore National Laboratory
}

\section{INTRODUCTION}

Atmospheric dispersion problems have received more attention with regard to global and homeland security than their conventional roles in air pollution and local hazard assessment in the post 9/11 era. Consequently, there is growing interest to characterize meteorology uncertainty at both low and high altitudes (below and above $30 \mathrm{~km}$, respectively). A 3-D Coupled Ocean Atmosphere Prediction System (COAMPS, developed by Naval Research Laboratory; Hodur, 1997) is used to address LLNL's task. The objective of this report is focused on the effort at the improvement of COAMPS forecast to address the uncertainty issue, and to provide new capability for high-altitude forecast.

To assess the atmospheric dispersion behavior in a wider range of meteorological conditions and to expand its vertical scope for the potential threat at high altitudes, several modifications of COAMPS are needed to meet the project goal. These improvements include (1) the long-range forecast capability to show the variability of meteorological conditions at a much larger time scale (say, a year), and (2) the model physics enhancement to provide new capability for high-altitude forecast.

\section{MODEL AND EXPERIMENT DESIGN}

COAMPS consists of a data assimilation system, a nonhydrostatic atmospheric forecast model, and a hydrostatic ocean model. In this study, we use only the atmospheric model, which is composed of a compressible form of the dynamics, nest-grid capability, and parameterizations of subgrid-scale turbulence, surface momentum and heat fluxes, explicit ice microphysics, subgrid-scale cumulus clouds, and shortwave and longwave radiation. The terrain-following vertical coordinate is also used to simulate flow over an irregular surface. The reader is referred to Chin et al (2004) for further details of LLNL version of COAMPS.

The model domain contains stretching grids in the vertical, with the grid size varied to maximize the grid

\footnotetext{
*Corresponding author address: Dr. Chin, Lawrence Livermore National Lab. (L-103), Livermore, CA 94550; e-mail: chin2@IInl.gov.
}

resolution at lower levels. The grid spacing of the lowest vertical layer is $4 \mathrm{~m}$, with each successive layer gradually increased to the altitude of $16.352 \mathrm{~km}$. Above this level, a uniform vertical grid size of $2000 \mathrm{~m}$ is specified up to the altitude of $34.352 \mathrm{~km}$ for the lowaltitude simulations. For the high-altitude simulations, the domain top is further extended to $65.352 \mathrm{~km}$ by adding additional uniform vertical grid points at the resolution of $2000 \mathrm{~m}$. In the horizontal, the single nest domain is used for monthly simulations over a period of one year to include the variability of meteorological conditions at different scales, ranging from diurnal, interseasonal, and seasonal cycles. In addition, three nested domains are adopted for daily forecasts over a period of 30 days for two months; January and July 2003. This experiment design is used to validate COAMPS long-range forecast capability, and to assess the influence of lateral boundary condition and grid resolution on the COAMPS forecast. Both zonal and meridional coordinates for first, second and third nested domains have 73,85 , and 127 grids, respectively. A uniform horizontal grid size of $36 \mathrm{~km}$ is used for the outer coarser mesh (nest_1) with a constant size ratio of three to define the inner nest grids. Therefore, the finest horizontal grid resolution of the third nested domain is 4 km (nest_3). Figures $1 \mathrm{a}$ and $1 \mathrm{~b}$ show the topography of nest_1 and nest_3 domains. Three locations marked as "N", "O", "S" across the Korea peninsula are selected for the detailed analysis in the long-range coarse resolution simulations (Fig. 1a).

Constant time steps of 90 and 45 seconds for nonsound and sound wave calculations, respectively, are used in the coarser grids for the time-splitting scheme. The time steps for the finer-grid domains are reduced proportionally to the nest-grid size ratio. The rigid boundary condition is imposed at the vertical boundary. A sponge-damping layer is placed over a depth of seven grid points below the model top to minimize the reflection of internal gravity waves off the rigid upper boundary. The Davies (1976) boundary condition is applied to the lateral boundaries with a nudging zone of seven grid points at each lateral boundary. A time filter with a coefficient of 0.2 is applied to control 
computational instability associated with the leapfrog time approximation in the model.

\section{INITIAL CONDITIONS}

To provide the capability for assessing the threat all over the world, NOGAPS (Navy Operational Global Atmospheric Prediction System) data are used for lowaltitude long-range simulations in this study. This data set has horizontal resolution of $1^{\circ}(\sim 100 \mathrm{~km})$ in both longitude and latitude directions, and is available in pressure levels up to $10 \mathrm{mb}(\sim 32 \mathrm{~km})$. Therefore, COAMPS forecast domain can be set up at any place of the globe. As a demonstration for a potential threat, this report presents COAMPS simulations with the Korea peninsula as the domain center over a period of one year between December 2002 and November 2003 (see Fig. 2). Another global data set from NASA (GEOS-4) is also used to expand COAMPS forecast capability for high altitudes. The GEOS-4 data are in the resolution of $1.25^{\circ}(\sim 125 \mathrm{~km}) \times 1^{\circ}(\sim 100 \mathrm{~km})$ in longitude and latitude directions, respective, and available in pressure levels up to $0.2 \mathrm{mb}(\sim 59 \mathrm{~km})$. COAMPS simulation with GEOS-4 data in this report only lasts for 1 day. The purpose of such short simulation is focused on the demonstration of new capability for high-altitude forecast.

Another set of high-altitude analysis data from NRL, G2S (ground to space, $0-170 \mathrm{~km}$ ) is under test as well. This data set is in the same horizontal resolution, but it has much higher vertical extent. Results from this skyhigh data set will be shown in a separate report.

\section{RESULTS}

4a. Low-Altitude Forecast

\section{4a.1 Validation of Long-Range Forecast}

The conventional interest of weather forecast is focused on the short-range (few days) prediction within the troposphere (e.g., below $10 \mathrm{~km}$ ) as a result of the predictability of limited-domain numerical weather prediction (NWP) models due to the inaccurate lateral boundary conditions from global circulation models. To address the variability of meteorological conditions for the application of concern, it is computationally impractical to perform daily forecasts for one year as planned in this study.

To overcome this computational inefficiency, another way to obtain the lateral boundary conditions is to use analysis data for the duration needed. The analysis data are in principle regarded as a ground truth of the atmospheric state. Therefore, the forecast error for a longer-range simulation is primarily attributed to the deficiency of model physics and/or numerical technique. Since the model physics in most existing NWP models is rather mature and well tested for low-altitude forecast, the major concern for the long-range NWP simulation is narrowed down to the mass conservation of model numerical scheme. To assess this issue, COAMPS has been used in our previous research for a monthly simulation of California winter precipitation. Results exhibited fairly good agreement with surface rain gauge measurements for the accumulated precipitation over the whole California domain (not shown). The moisture budget of this monthly simulation over the whole model domain showed that the error between the source and sink terms grew to $5 \%$ in the first week. Afterward, this error quickly dropped to $2 \%-3 \%$, and remained at this level throughout the rest of the period. This suggests that the mass conservation of COAMPS did a pretty good job for the long-range simulation. Therefore, the model solution would not be biased by the artificial solution caused by the mass conservation.

With our earlier assessment on the mass conservation check of COAMPS for the long-range simulation, the same methodology is applied to this study for 12 monthly simulations to gauge the variability of meteorological conditions over the given area of concern. Results of monthly COAMPS simulations are validated using the daily forecast, which has been well tested with high forecast skill for short-range prediction.

Figures 3 and 4 show the differences of wind prediction between long- and short-range coarser resolution simulations $(\Delta x=36 \mathrm{~km})$ at lower $(700 \mathrm{mb} \sim 3$ $\mathrm{Km})$ and higher $(200 \mathrm{mb} \sim 12 \mathrm{~km}$ ) troposphere for the winter (Figure 3) and summer (Figure 4) months, respectively. Due to the use of analysis data for providing more accurate lateral boundary conditions, the long-range simulation near the end of the month exhibits fairly good agreement with the daily forecast at both wind direction (in streamlines) and speed (in color bars) on the corresponding day. Similar agreement is also seen on other days during the one-month period (not shown). This comparison provides an important support to lay a solid foundation of our experiment design for this research.

\section{4a.2 Variability of Meteorological Conditions}

Due to the nature of atmospheric dispersion problem, the variability of meteorological conditions is mainly referred to as the variation of horizontal winds in this report. To gauge the temporal variability of meteorological conditions, both the mean state and the 
standard deviation are important to illustrate the variation of horizontal winds. The $X-Y$ cross-sections of monthly mean and standard deviation of horizontal winds (with respect to the monthly mean) at different altitudes for four selected months are used to show their seasonal variations. The selected altitudes are located at $9.95 \mathrm{~km}, 3.15 \mathrm{~km}$ and $10 \mathrm{~m}$ to assess the variability of jet stream, synoptic-scale front, and near-surface local forcing (e.g., terrain and sea-land breeze), respectively.

The local trend for the winds is a strong synoptic forcing of westerly winds in the winter, which tends to wash out the local off-shore/on-shore wind patterns associated with coastal regions. In the summer the synoptic forcing is weaker at lower altitudes revealing the off-shore/on-shore wind patterns associated with the local coastal terrain (see Fig. 5). The seasonal migration of jet stream and the fluctuation of its intensity are replicated in our simulation over the Northeast Asia (Fig. 6). The strongest jet stream appears in winter and is located to the south of Japan. Afterwards, the jet stream weakens and retreats to the north with the weakest intensity in summer. This process reverses in the second half of the year leading to the southward movement of the jet stream between the summer and the following winter. Similar evolution and fluctuation of the jet stream in the same area can also be seen in other years, such as in the year of 2001 using ECMWF re-analysis data at $250 \mathrm{mb}(\sim 10 \mathrm{~km})$. As a whole, the prevailing wind over the Korean peninsula is westerly at the jet stream level throughout the year while its speed changes as the jet stream migrates with time. In contrast to the mean state, the strongest spread of horizontal winds appears in the transition seasons (spring and fall) as a result of the transient feature of the jet stream (see April and October in Fig. 7).

Figure 8 exhibits the monthly means of the horizontal winds at the altitude of $3.15 \mathrm{~km}$ over a seasonal cycle. This altitude is chosen to assess the variation of the synoptic-scale front movement and intensity. The thick red lines in Figure 8 indicate the locations of wind shift zone, which can be viewed as the averaged position of the front. This figure illustrates that the strongest front exists in winter and can propagate southeastward beyond the Korean peninsula from the Northeastern China. Therefore, northwesterly winds prevail over the entire Korean peninsula. As the time evolves from winter to spring, the front weakens and retreats from its eastward movement. The weakening of the front intensity continues into the summer and the track of the front path shrinks to the northwest of the Korean peninsula. Afterward, the front becomes stronger again and continues its southeastward movement in the second half of the year. The temporal variance of horizontal winds at this level is dominated by the front activity (Fig. 9). Therefore, the weakest temporal variance occurs in summer.

Unlike the higher troposphere, the near-surface winds exhibit more seasonal variation over the Korean peninsula due to the presence of dominant southerly flow from the East China Sea in summer (Fig. 10). Therefore, noticeable directional wind shear appears in the lower troposphere of this area as the summer monsoon flow develops. Although the diurnal variation of local forcing associated with terrain and coastline becomes evident in the summer time, this smaller temporal scale feature is hard to be seen in the monthly mean state due to its spatial oscillating properties, such as sea-land breeze and up- and down-valley wind. While surface winds vary more from season to season as evident in Figure 10, the standard deviation of horizontal winds within its own month exhibits small spread of surface winds compared to the monthly spread seen for winds aloft (see Figs. 7, 9 and 11). This small variation indicates that the magnitude of surface wind variability is still much weaker than its counterpart in the higher troposphere.

Figure 12 shows the vertical profiles of mean and standard deviation of horizontal winds, which illustrate the temporal variability of winds at the central portion of the Korean peninsula, marked as the point $\mathrm{O}$ in Fig. $1 \mathrm{a}$. The jet stream located at $\sim 12 \mathrm{~km}$ clearly shows a seasonal variation with the maximum intensity for the winter months and the minimum intensity for the summer months. However, the summer months exhibit relatively stronger wind spread than their winter counterparts due to the prominent spatial transient feature of horizontal winds.

Figure 13 shows the time series of 10_m meridional wind and 2_m temperature at the northern, central and southern Korea (as marked as "N", "O", and "S" in Fig. 1a, respectively) for the winter and summer months. These plots can provide information for the evolution of both synoptic-scale (e.g., the frontal passage) and localscale (e.g., diurnal variation) circulations. The wind shift from southerly (positive) to northerly (negative) followed by strong temperature drop in the winter month indicates the passage of a synoptic-scale front with the period of 3 - 5 days. Based on these time series, the front can 
propagate to the southern end of the Korean peninsula, where the warmer winter temperature also allows weaker diurnal variation to occur (see Figs. 13a, 13c, and $13 e$ ). In contrast, the diurnal variation of both wind and temperature fields dominates in the summer month all over the whole Korean peninsula (Figs. 13b, 13d, and 13f). The sharp contrast of near-surface atmospheric behavior between the winter and summer months is mainly determined by the temperature filed. The higher temperature in the summer time would enhance the local forcing from the coastline and terrain for sea-land breeze and up-down valley wind while the colder temperature in winter would suppress the diurnal variation.

\section{4a.3 Boundary Condition and Grid Resolution Impact}

Due to the computational cost of high-resolution simulations, it is impractical to perform such simulations over a long period of time to assess the variability of meteorological conditions. Therefore, it is imperative to evaluate the impact of grid resolution along with boundary condition to the long-range forecast by performing short-range high-resolution simulations over a period of two months; one for January 2003 and the other for July 2003.

Figure 14 exhibits the daily contrast of horizontal wind forecasts located at 500 meters above the ground for January and July 2003 between long-range coarserresolution (12 km) and short-range finer resolution (4 $\mathrm{km}$ ) simulations at the location near the central Korea peninsula marked as the point $\mathrm{O}$ in Fig. 1a. Results indicate that on some days there are considerable differences in the near surface daytime and nighttime wind forecasts.

To explore the cause of these differences, detailed comparisons of time-to-time and layer-to-layer forecasts from long- and short-range coarser-resolution, and short-range finer-resolution simulations are shown in Figure 15 through Figure 18. Figure 15 shows horizontal cross-sections of the contrast for the 10_m wind forecast on two days; one for January 16, 2003 and the other for July 16,2003 . The main focus is concentrated on the location near the point $\mathrm{O}$ as shown in Fig. 1a. The difference of long- and short-range coarser-resolution simulations reflects the impact from the lateral boundary condition, and the contrast between short-range coarser- and finer-resolution simulations indicates the influence from the grid resolution. This figure illustrates two types of differences in the surface wind predictions; one caused by grid resolution on a winter day (e.g., Figs 15 a-c) and the other caused by the boundary condition on a summer day (e.g., Figs 15 d-e).

The same comparison is also done for the last day of the month (Fig. 16), and shows only one type of difference in the surface wind predictions. Heuristically examining the winds on these plots reveals that the most noticeable contrast in the wind vectors is caused by grid resolution differences for the summer day in this case.

Further comparison is performed at higher altitudes. Figure 17 illustrates results at the height of $700 \mathrm{mb}(\sim 3$ $\mathrm{km})$. As in the 10_m wind of Figure 16, the most significant difference occurs on the summer day. However, unlike the $10 \mathrm{~m}$ winds, the $700-\mathrm{mb}$ wind difference is related to the boundary condition, which leads to a stronger synoptic-scale clock-wise circulation (high pressure system) to the east of the Korean peninsula in the long-range coarser-resolution simulation (see Figs $17 d$ and 17e). To investigate the impacts of boundary condition and grid resolution further at higher altitudes, the same comparison is done above $700 \mathrm{mb}$, and the results at higher altitudes (e.g., 500 $\mathrm{mb}, \sim 5 \mathrm{~km}$ ) barely show difference on both winter and summer days (Fig. 18).

Generally speaking, this limited examination of wind forecasting indicates that both boundary condition and grid resolution can affect forecast performance. For the scale of interest in the mesoscale simulation, the boundary condition impact can exist in both the lower atmosphere and near the surface while the grid resolution impact mainly appears near the surface as a result of local forcing (such as terrain and coastline).

To minimize the bias of a limited number of comparisons, monthly mean comparison of horizontal wind forecast at different altitudes from both long-range coarser-resolution and short-range finer-resolution simulations are also included using the forecast data available every 3 hours for 30 days. As seen in Figs. 8, 10 , and 19 for the wind forecast at $10 \mathrm{~m}$ and $3.15 \mathrm{~km}$ altitude, the close agreement of the monthly mean of wind forecast at the height of $3.15 \mathrm{~km}$ for both winter and summer months suggests that the impact of boundary condition on forecast performance is small. In contrast, the monthly mean of the near surface wind (10 $\mathrm{m}$ ) exhibits noticeable difference in July, such as at the location near the central Korea caused by local terrain, and the location at the southeast corner of the Korean 
peninsula due to the stronger sea breeze in the highresolution forecast (Figs 10a and 10c, and Figs. 19a and 19b).

In summary, this limited analysis of boundary condition and the grid-resolution illustrates that for both winter and summer months, the impact of the boundary conditions and of the grid resolution on forecast performance in the troposphere is limited. This, in turn, implies that the accuracy of the analysis data is acceptable for use as boundary conditions in limited domain long-range simulations. This same conclusion can be extended to the higher altitudes (e.g., above 10 $\mathrm{km})$, where the atmospheric process is almost uninfluenced by the local terrain and coastline.

\section{4b. High-Altitude Forecast}

The horizontal grid resolution and grid mapping of NASA GEOS-4 data are different from those used in COAMPS. In addition, this data set is a new product used in NARAC numerical weather forecast. Therefore, a benchmark test is set up to assess the performance of GEOS-4 data conversion and data quality by comparing the results with the forecast from the NOGAPS data set.

Figure 20 exhibits the horizontal wind comparison of 18_hour forecasts from NOGAPS and GEOS-4 data in the higher and lower troposphere. The close resemblance of the results from given meteorological conditions on September 15, 2002 indicate the forecast quality of GEOS-4 data is as good as the one using NOGAPS, which has been widely adopted in numerical weather prediction for decades. This promising outcome greatly promotes the potential of GEOS-4 data for use in future weather forecast by providing the prediction above the conventional limit of $10 \mathrm{mb}(\sim 32$ $\mathrm{km}$ ) for further applications in global and homeland security scenarios.

To make good use of GEOS-4 data on its unique higher altitude coverage, the COAMPS model needs further modification to expand its conventional focus in the prediction below $32 \mathrm{~km}$. To this end, the first step of modification is to extend the climatology specification from $0.2 \mathrm{mb}(\sim 59 \mathrm{~km})$ to $0.0003 \mathrm{mb}(\sim 104$ $\mathrm{km})$. Secondly, the formulation to compute saturated mixing ratio of water vapor, $q_{s}=\frac{0.622 \bullet e_{s}}{p-e_{s}}$, is also changed. The calculation of saturated moisture pressure $\left(e_{s}\right)$ in COAMPS is based on a look-up table, which uses temperature dependence. However, this approach would fail for the high-altitude forecast above $32 \mathrm{~km}$ since the temperature in the stratosphere would continuously increase to the level near the stratopause $(\sim 47 \mathrm{~km})$ with the magnitude as high as the ones seen near the surface. Therefore, COAMPS would significantly over-estimates the saturated moisture pressure in the higher stratosphere such that the saturated moisture pressure becomes smaller than the air pressure $(p)$. The resulting negative mixing ratio of water vapor would cause the crash of microphysics calculation. This problem is solved by using Teten's formulation (Chin, 1994; Chin et al., 1995) to compute the saturated mixing ratio of water vapor directly. The modified formulation uses both air temperature and pressure so that the new scheme can distinguish the lower troposphere from the higher stratosphere in the calculation of saturated mixing ratio of water vapor.

Although the GOES-4 data set has its unique feature in providing meteorological conditions at high altitudes, it also raises a new difficulty in that validating model forecast at higher altitudes is problematic. In this regard, the analysis fields of GEOS-4 data are assumed to be the ground truth of atmospheric state. This assumption is fairly justified in practice, and becomes even more realistic at higher altitudes since only large-scale variations exit at these altitudes.

The remaining question for the COAMPS forecast at higher altitudes is whether the model physics is appropriate for simulating stratosphere due to the lack of other atmospheric processes. For example, chemistry, which is believed to have important impact on the large-scale circulation, is not considered by the COAMPS forecasts. With the modified version of COAMPS, the close resemblance of COAMPS forecast with GEOS-4 analysis winds from the upper troposphere to the whole stratosphere illustrates very promising progress in promoting new forecast capability at higher altitudes, at least for the shorter temporal scale (Fig. 21).

\section{SUMMARY}

The COAMPS model has been used to assess the meteorology uncertainty for global and homeland security applications. The focus of this report is to show the long-range simulation capability of COAMPS for providing the variability of meteorological conditions for the computational efficiency. The success of using NASA GEOS-4 data and improved COAMPS physics for high-altitude simulation also demonstrates the further expansion of COAMPS applications.

Results clearly indicate that the variability of meteorological conditions below $30 \mathrm{~km}$ over the Korean peninsula exhibits its maximum at the jet stream level. Although the strongest jet stream appears in the winter in response to the intense horizontal temperature gradient in the troposphere, the maximum variability of horizontal winds occurs in the transition months between winter and summer as a result of the transient 
feature of the jet stream. Unlike the dominance of synoptic-scale front activity in the cold season, the diurnal cycle associated with local surface forcing, such as terrain and coastline becomes evident in the warm temperature regime while its contribution to the temporal variability of horizontal winds is still much smaller than the larger-scale features, such as the front and the jet stream.

Results also show that the accuracy of the analysis data is reasonably acceptable for use in the long-range simulation as the lateral boundary conditions. Although there may exist some difference between long- and short-range forecast in response to the phase error of physical phenomena as a result of the imperfect boundary condition, this impact is generally small. Therefore, the performance of long-range simulation can be as good as the short-range forecast in particularly away from the surface layer. However, the difference of long- and short-range forecast can be significant as the local surface forcing (such as terrain and coastline) becomes dominant in the summer time. Then, higher horizontal resolution of long-range simulation is highly recommended to provide better forecasts near the surface for the area with terrain and coastline.

Acknowledgments. The authors wish to thank Dr. GiKong Kim for providing us NASA GEOS-4 data to make high-altitude forecast available at LLNL. This work was supported by LLNL LDRD project (03-ERD-039) and the U.S. Department of Energy National Advisory Release Assessment Program, and conducted under the auspices of the U.S. Department of Energy by the University of California, Lawrence Livermore National Laboratory under Contract W-7405-Eng-48.

\section{REFERENCES}

Chin, H.-N. S., 1994: The impact of the ice phase and radiation on a midlatitude squall line. J. Atmos. Sci., 51, 3320-3343.

Chin, H.-N. S., Q. Fu, M. M. Bradley and C. R. Molenkamp, 1995: Modeling of a Tropical Squall Line in Two Dimensions: Sensitivity to Radiation and Comparison with a Midlatitude Case. J. Atmos. Sci., 52, 3172-3193.

Chin, H.-N. S., M. J. Leach, G. A. Sugiyama, J. M. Leone Jr., H. Walker, J. S. Nasstrom, and M. J. Brown, 2004: Evaluation of an urban canopy parameterization in a mesoscale model using VTMX and URBAN 2000 data. Mon. Wea. Rev (in revision).

Hodur, R., 1997: The Naval Research Laboratory's coupled ocean-atmospheric mesoscale prediction system (COAMPS). Mon. Wea. Rev., 125, 14141430. 

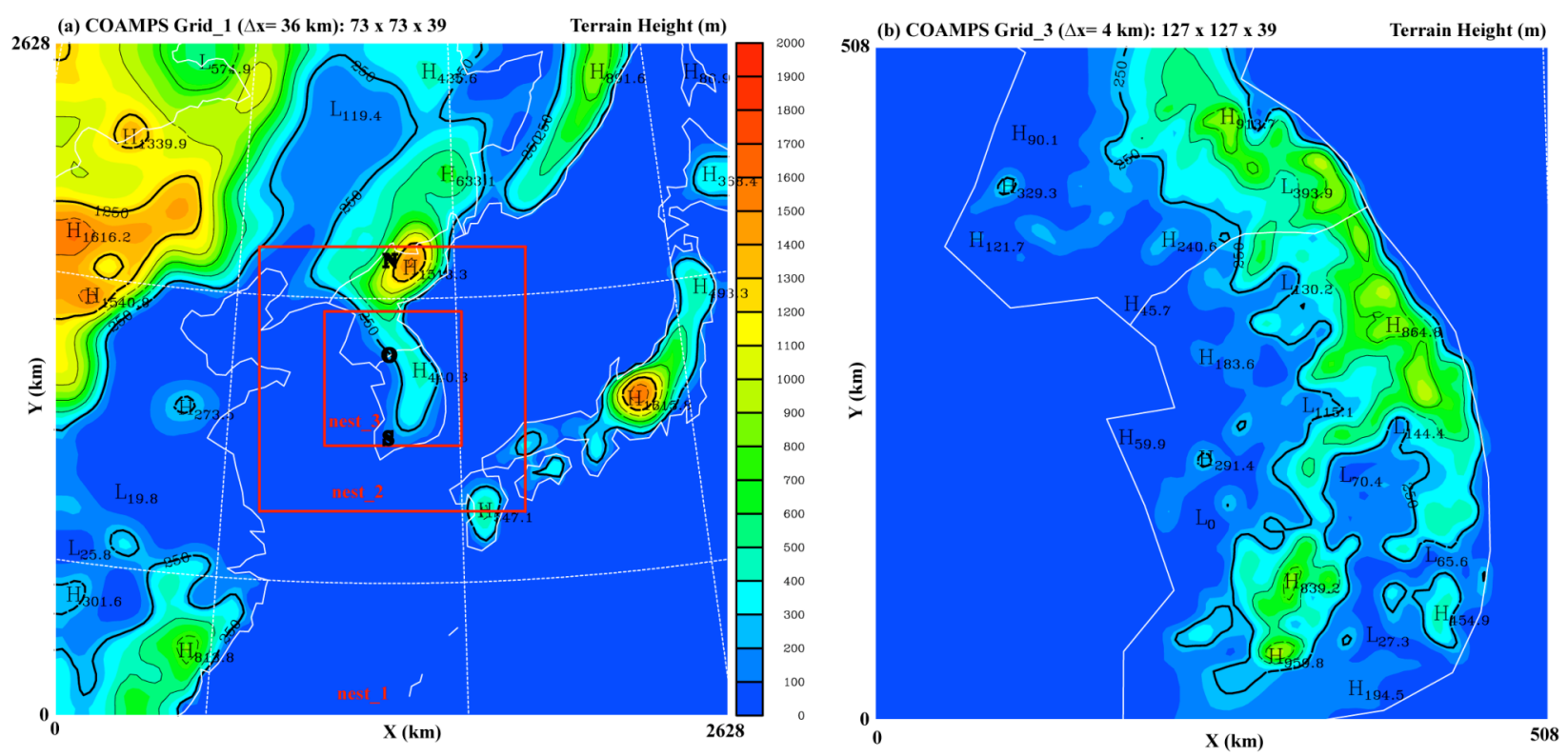

Fig. 1. Topography of the model domain. (a) nest_1 domain with grid resolution of $36 \mathrm{~km}$, and (b) nest_3 domain with grid resolution of $4 \mathrm{~km}$. The symbols of point $\mathrm{S}, \mathrm{N}$ and $\mathrm{O}$ mark the locations represent the southern, central, and northern parts of the Korean peninsula. 


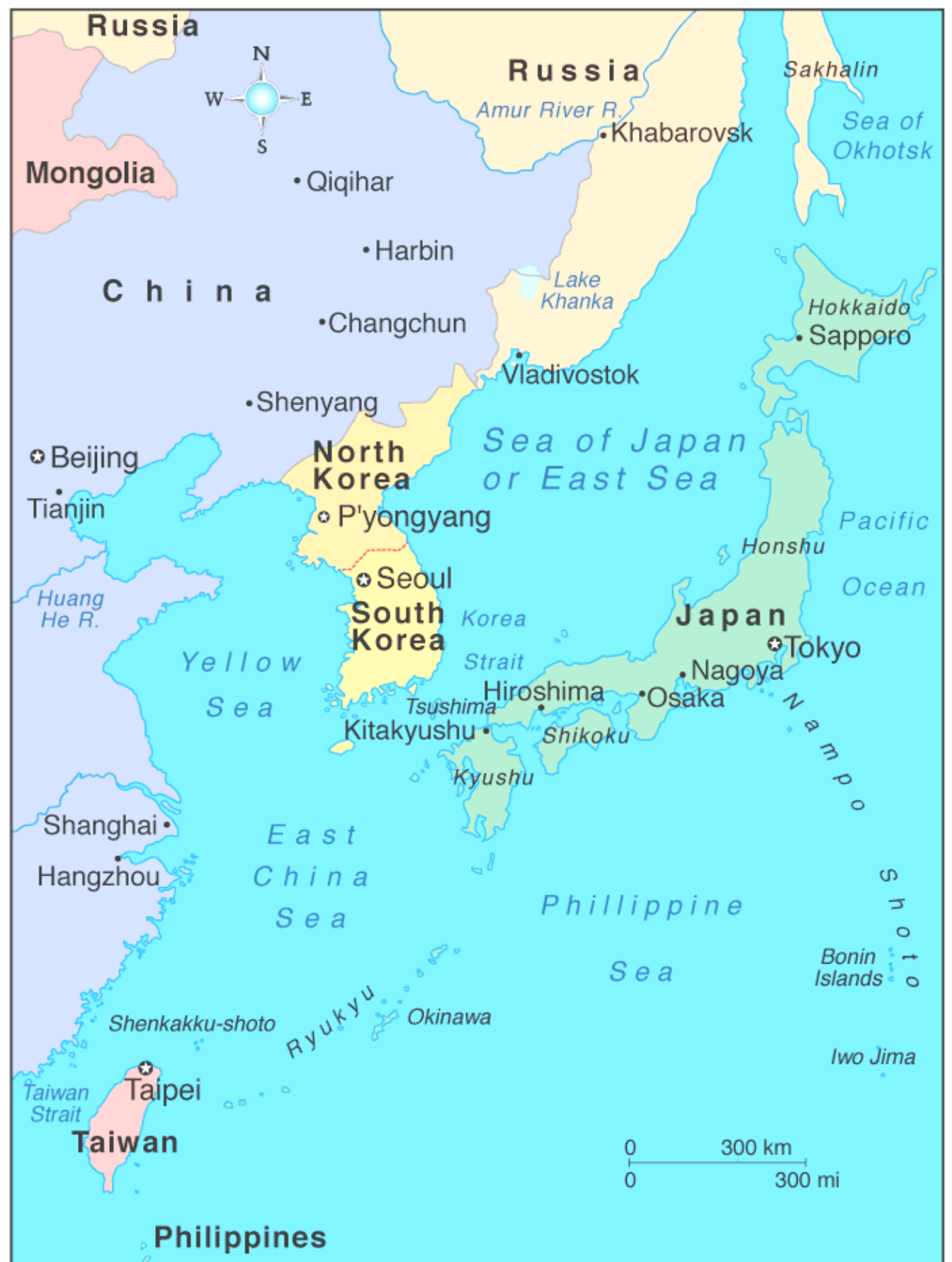

Fig. 2. Political map of region of concern. Note that the "N", "O" and "S" indicate points where specific temperature and wind forecasts are studied. 


\section{Horizontal Wind Forecast $(\mathrm{m} / \mathrm{s})$ at $06 \mathrm{Z}$ January 30, 2003}

30-day forecast

(a) $702 \mathrm{~h}$ forecast from $\mathbf{2 0 0 3 0 1 0 1 0 0}$

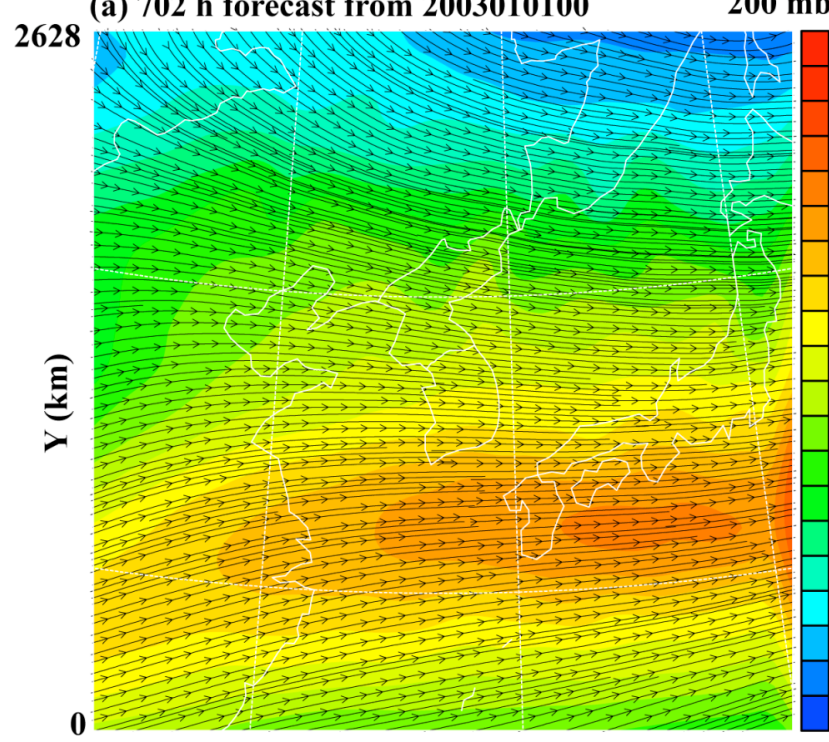

(c) $702 \mathrm{~h}$ forecast from 2003010100

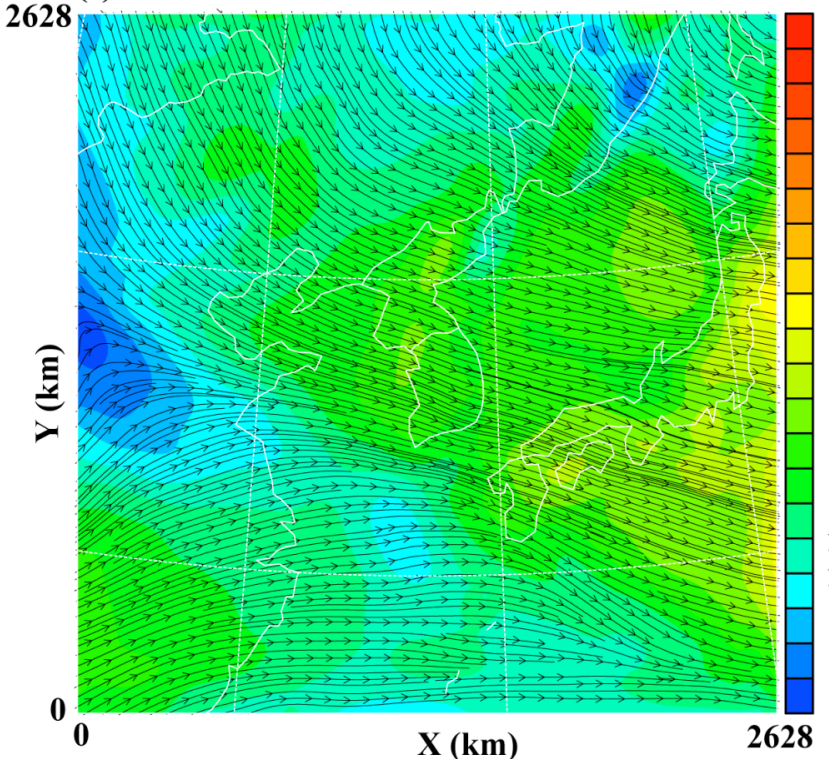

6-h forecast

(b) $6 \mathrm{~h}$ forecast from $2003013000 \quad \Delta \mathrm{x}=36 \mathrm{~km}$

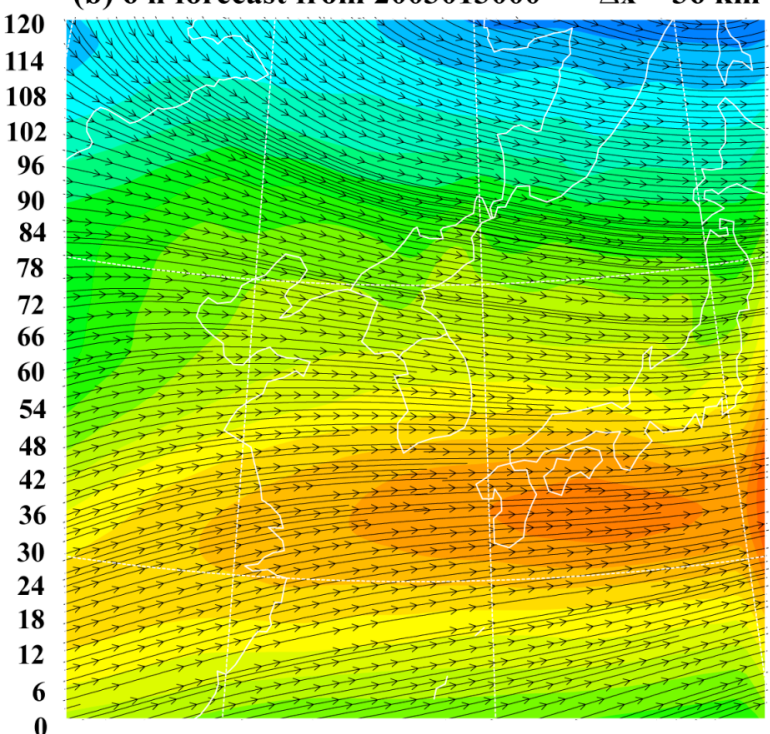

(d) $6 \mathrm{~h}$ forecast from $2003013000 \quad \Delta \mathrm{x}=36 \mathrm{~km}$

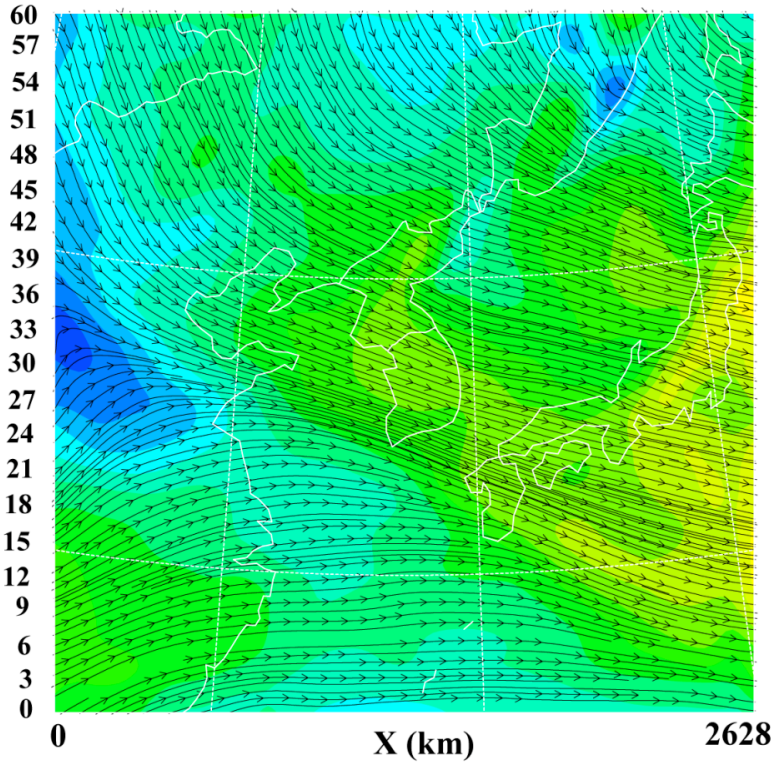

Fig. 3. Horizontal cross-sections of long- (left panels) and short-range (right panels) wind forecasts from the coarse resolution simulations valid at 06 GMT January 30, 2003. Upper panels are the forecasts at $200 \mathrm{mb}(\sim 12 \mathrm{~km})$, and lower panels for the forecasts at $700 \mathrm{mb}(\sim 3 \mathrm{~km})$. 
Horizontal Wind Forecast $(\mathrm{m} / \mathrm{s})$ at $06 \mathrm{Z}$ July 28, 2003

\section{8-day forecast}

(a) $654 \mathrm{~h}$ forecast from 2003070100

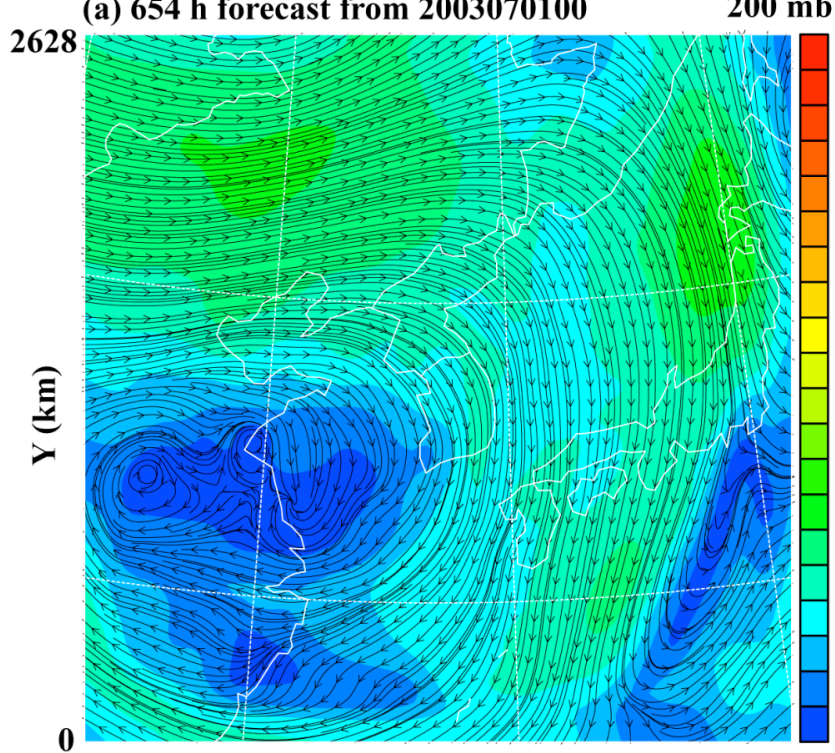

(c) $702 \mathrm{~h}$ forecast from $\mathbf{2 0 0 3 0 1 0 1 0 0}$

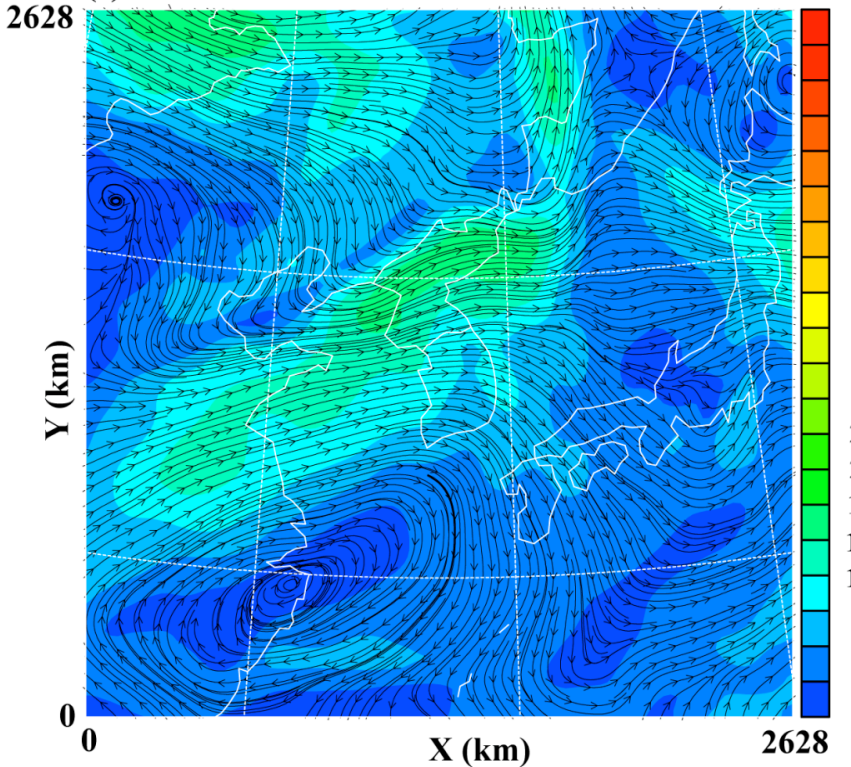

6-h forecast

(b) $6 \mathrm{~h}$ forecast from $200307280000 \Delta x=36 \mathrm{~km}$

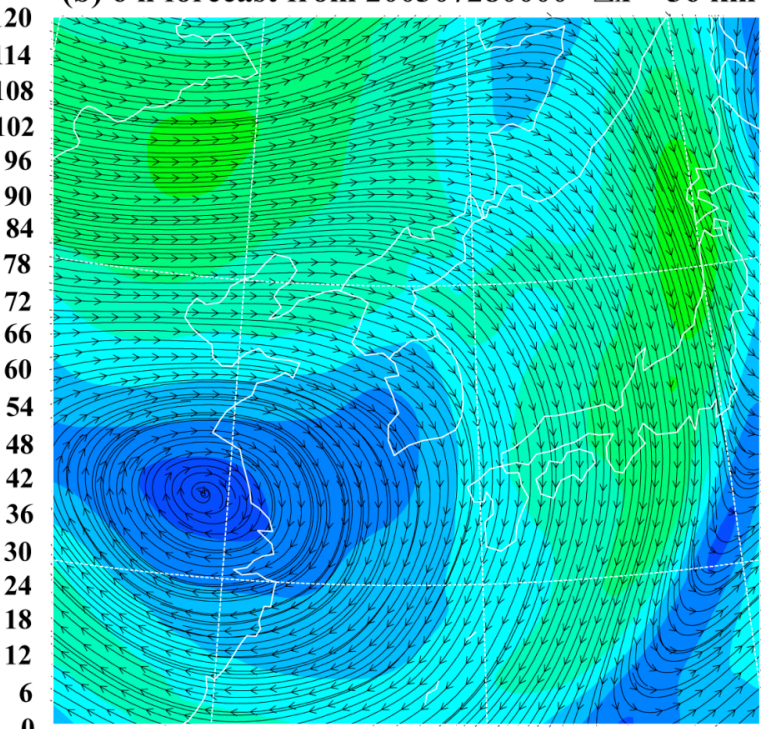

(d) $6 \mathrm{~h}$ forecast from $2003013000 \quad \Delta x=36 \mathrm{~km}$

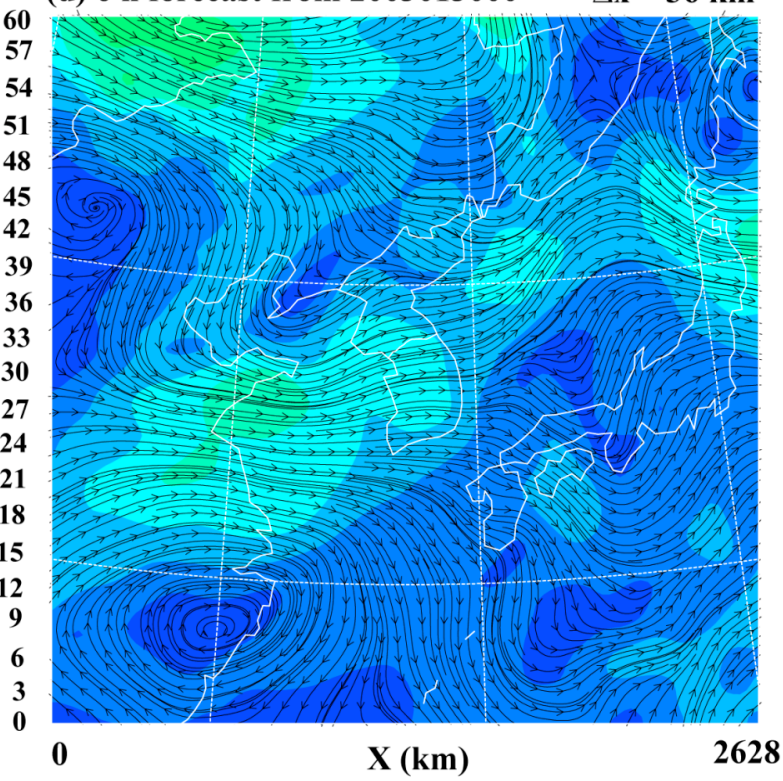

Fig. 4. Same as Fig. 3, except for the summer time case, valid at 06 GMT July 28, 2003. 


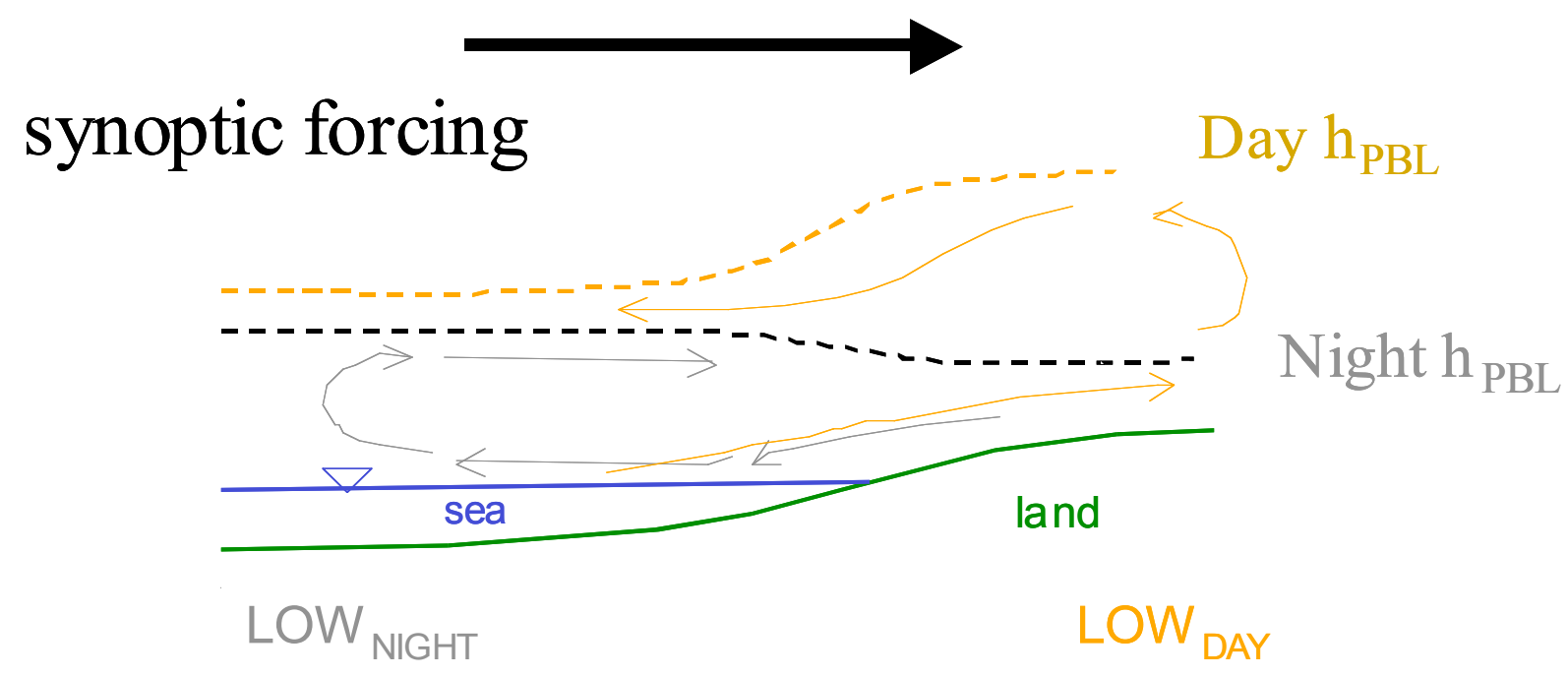

Fig. 5. A conceptual schematic of the local meteorological conditions for a coastal location. For Northeast Asia, the synoptic forcing is westerly in nature, while local wind patterns follow the on-shore/off-shore wind patterns associated with coastal locations: daytime winds from the sea brings air landward which convects to the top of the boundary layer (hPBL) and then moves aloft towards the sea; conversely, nighttime winds move off air off of the land, convecting at sea and then move aloft landwards. Synoptic forcing dominates high and low altitude winds in the winter, while synoptic winds dominate only high altitudes in the summer. 


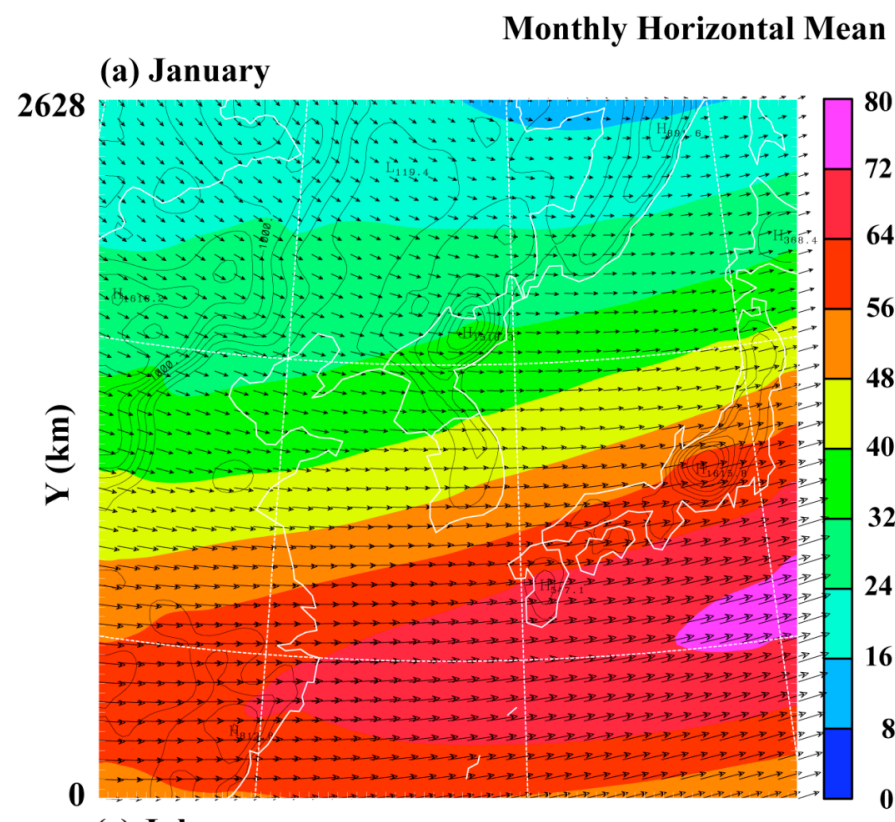

(c) July

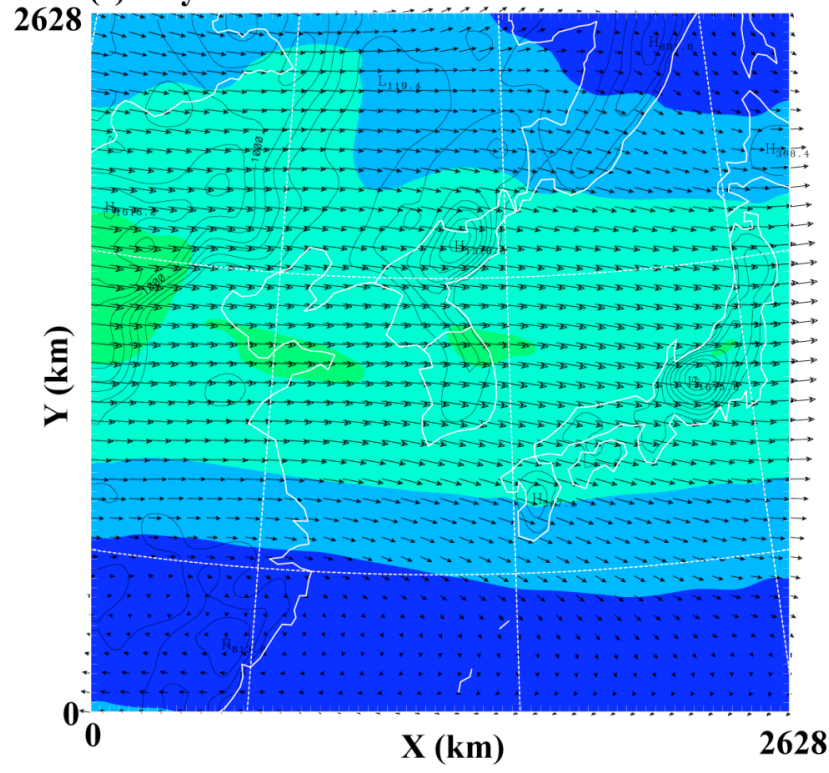

(d) October

(b) April
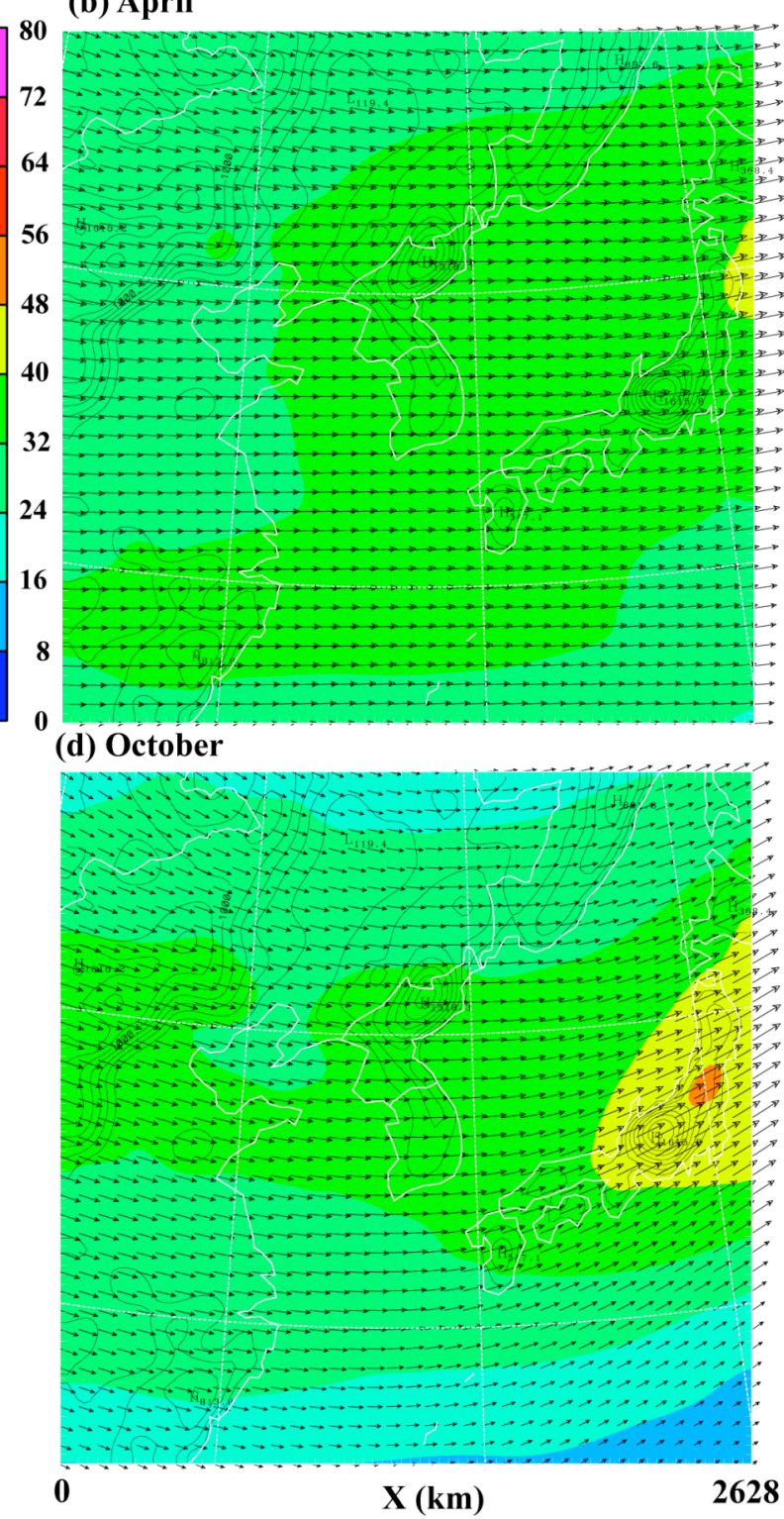

Fig. 6. Monthly mean of horizontal winds at $9.95 \mathrm{~km}$ altitude. (a) January, (b) April, (c) July, and (d) October. The color bar shows the magnitude of winds in unit of $\mathrm{m} / \mathrm{s}$, and the contours represent the topography. 


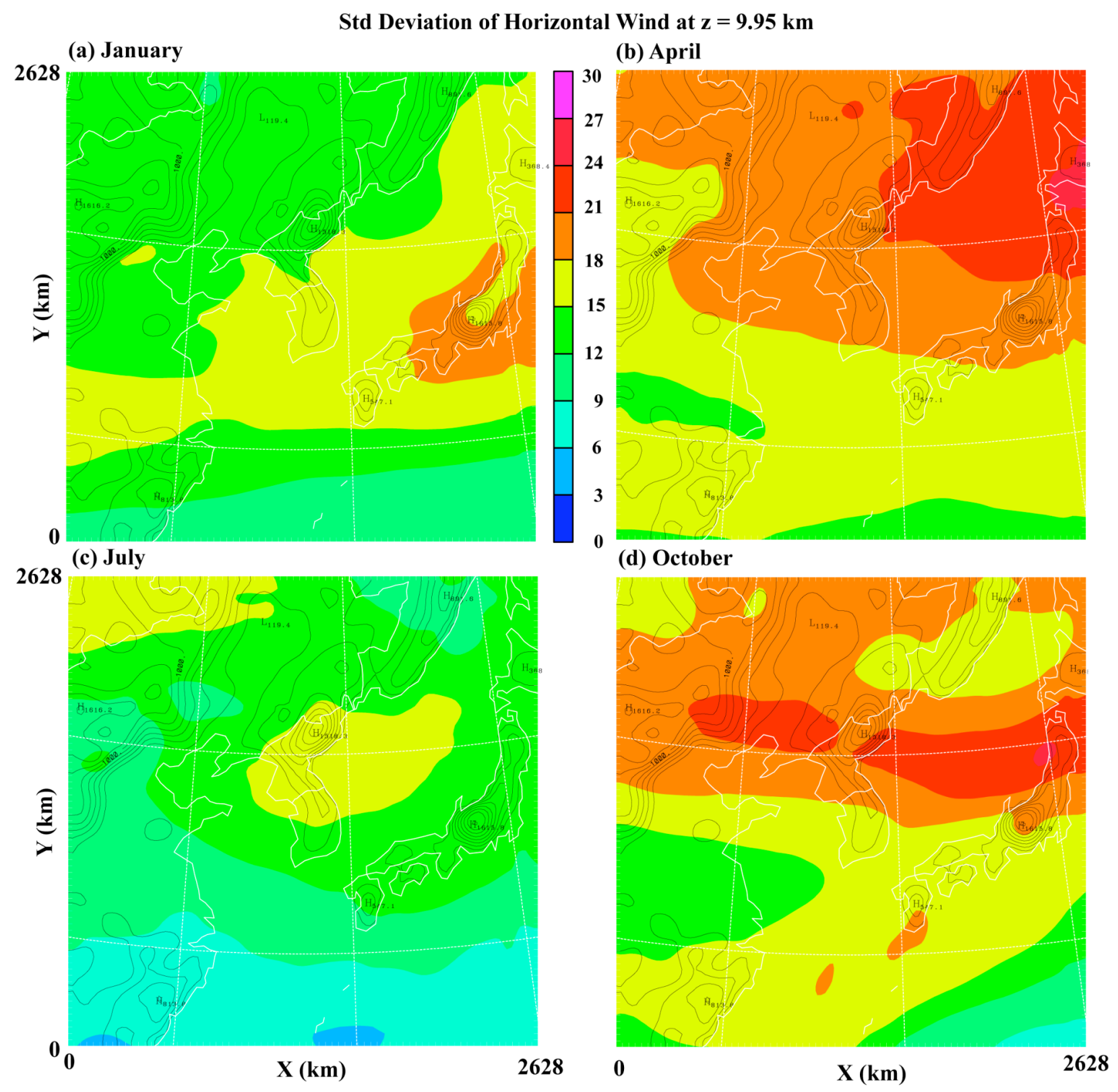

Fig. 7. Same as Fig. 6, except for the standard deviations of horizontal winds in unit of $\mathrm{m} / \mathrm{s}$. 


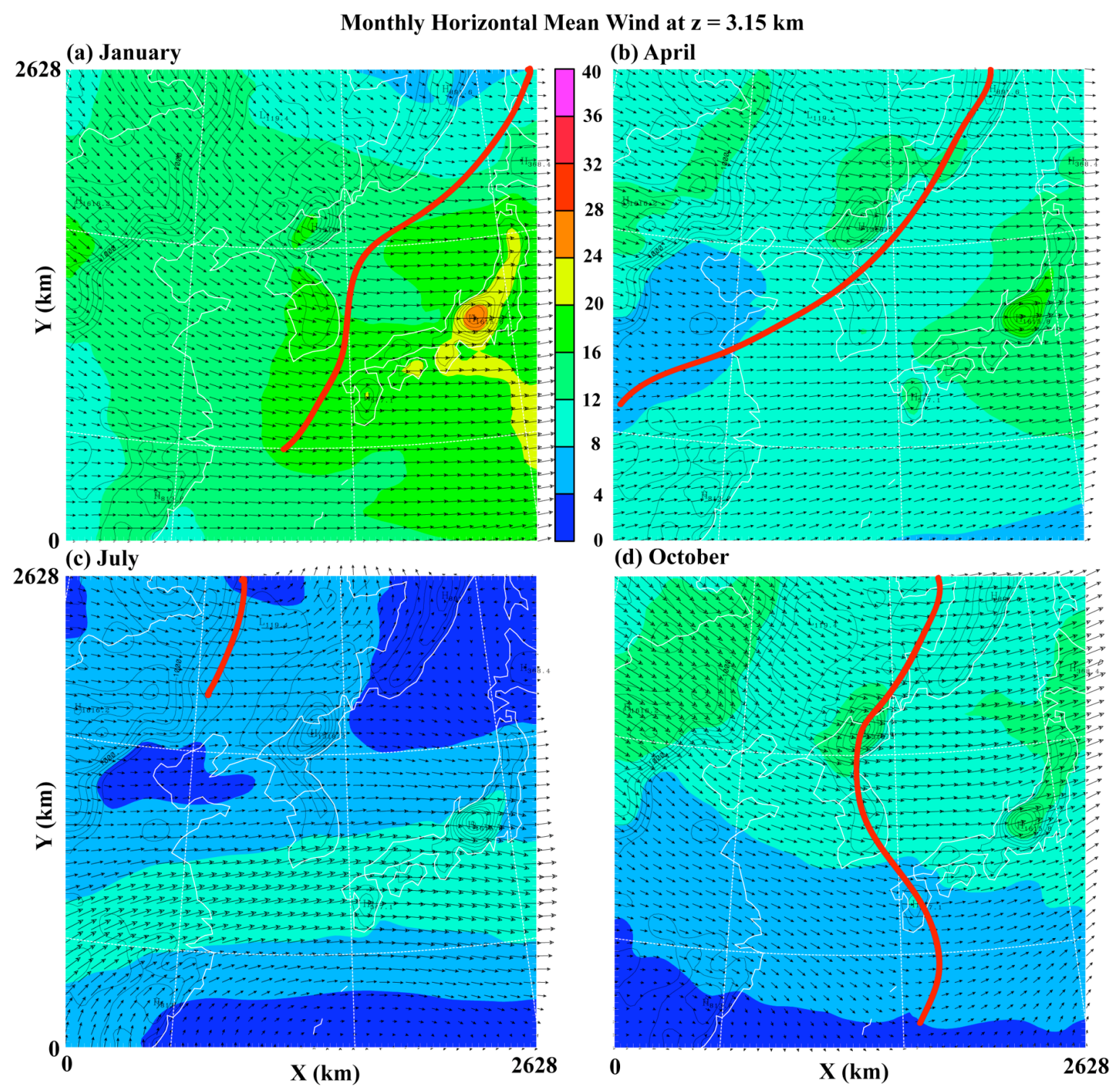

Fig. 8. Same as Fig. 6, except for the monthly means of horizontal winds at $3.15 \mathrm{~km}$ altitude. The thick red lines mark the wind shift zones, representing the averaged positions of the synoptic-scale fronts. 


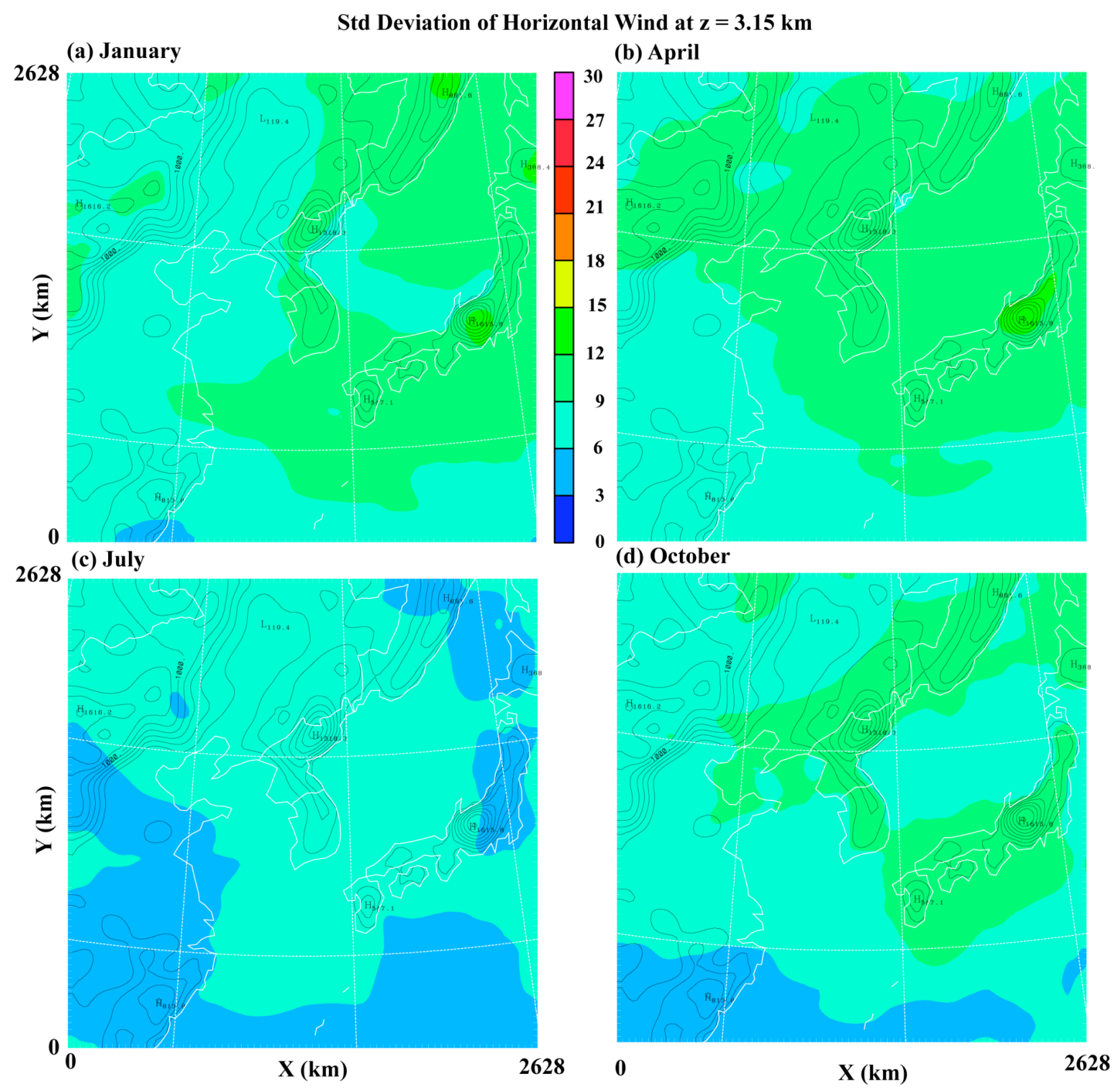

Fig. 9. Same as Fig. 7, except for the standard deviation of horizontal winds at $3.15 \mathrm{~km}$ altitude. 
(a) January

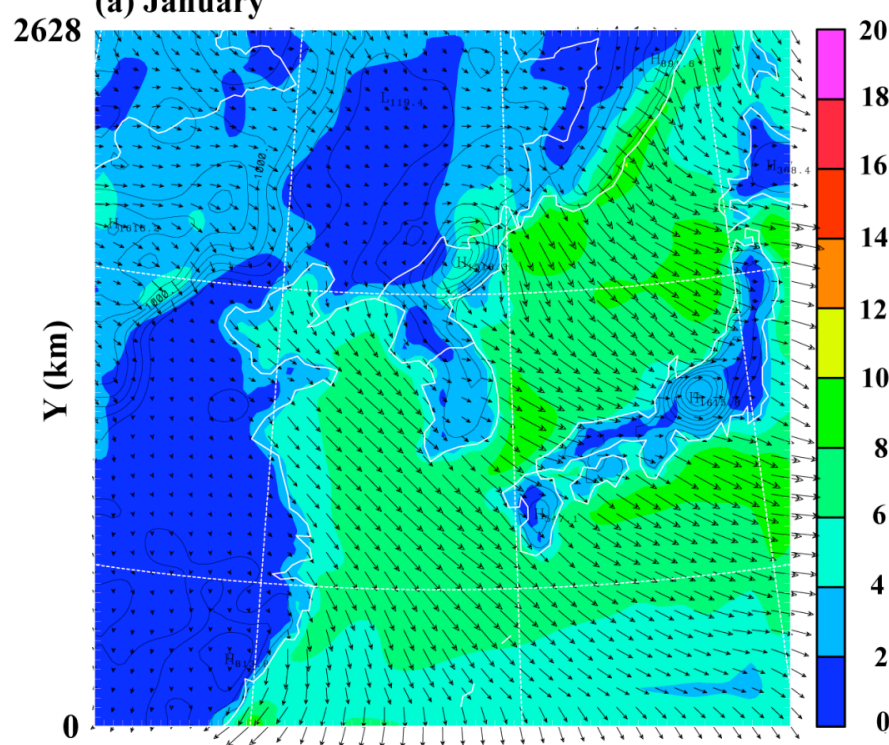

(c) July

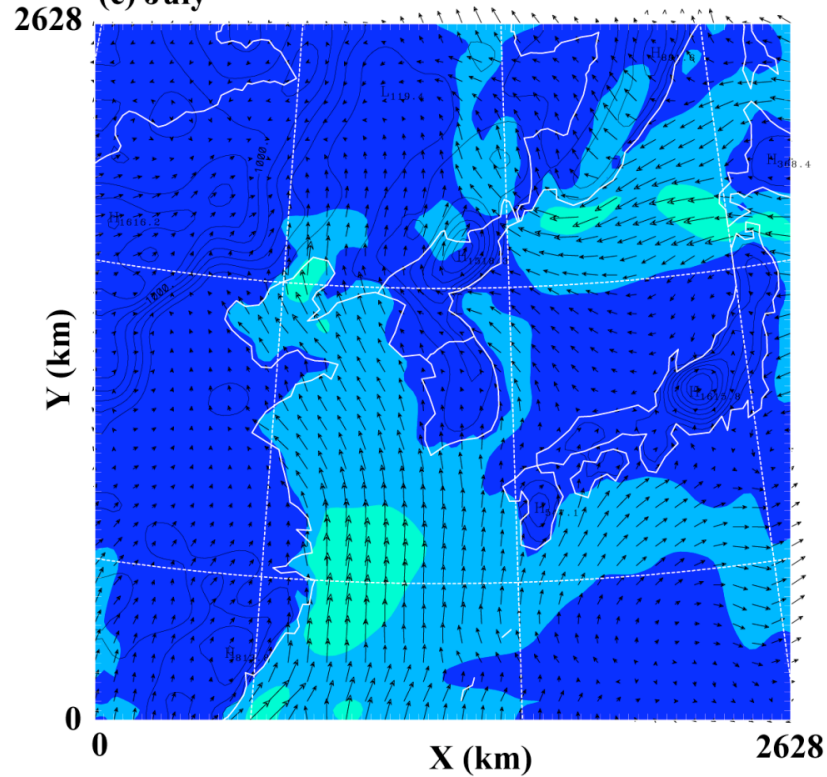

Monthly Horizontal Mean Wind at $\mathrm{z}=10 \mathrm{~m}$

(b) April

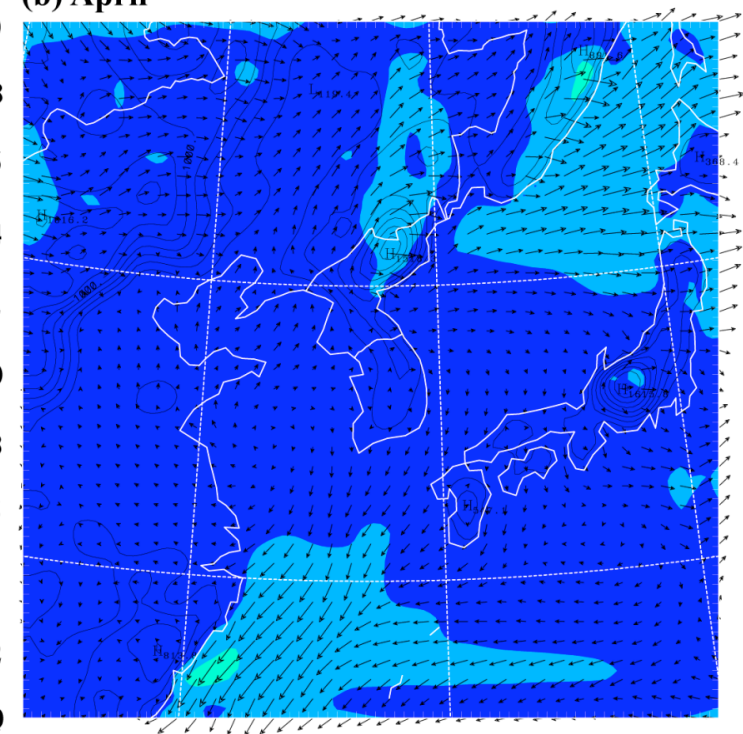

(d) October

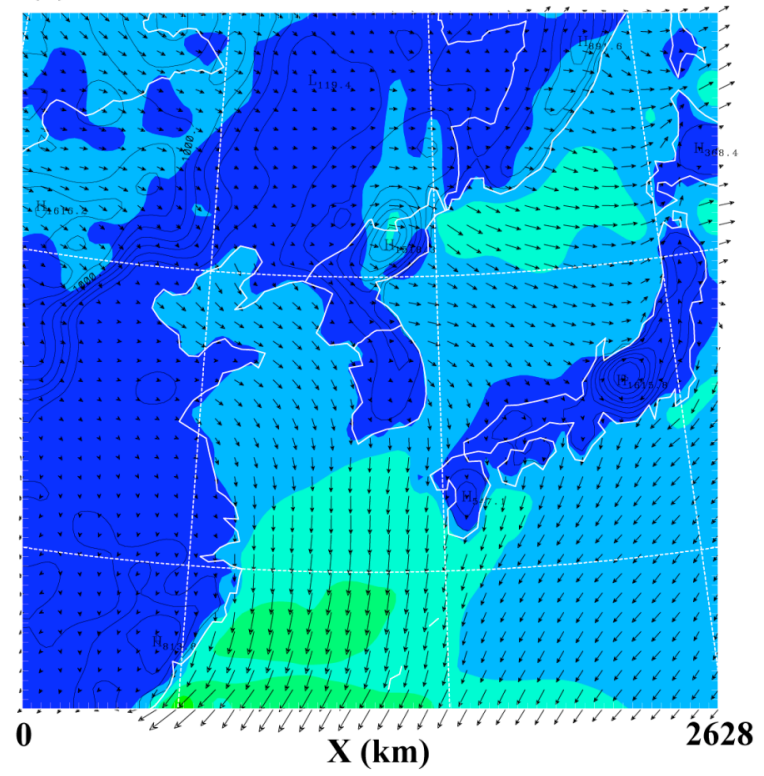

Fig. 10. Same as Fig. 6, except for the monthly means of horizontal winds at $10 \mathrm{~m}$ altitude. 


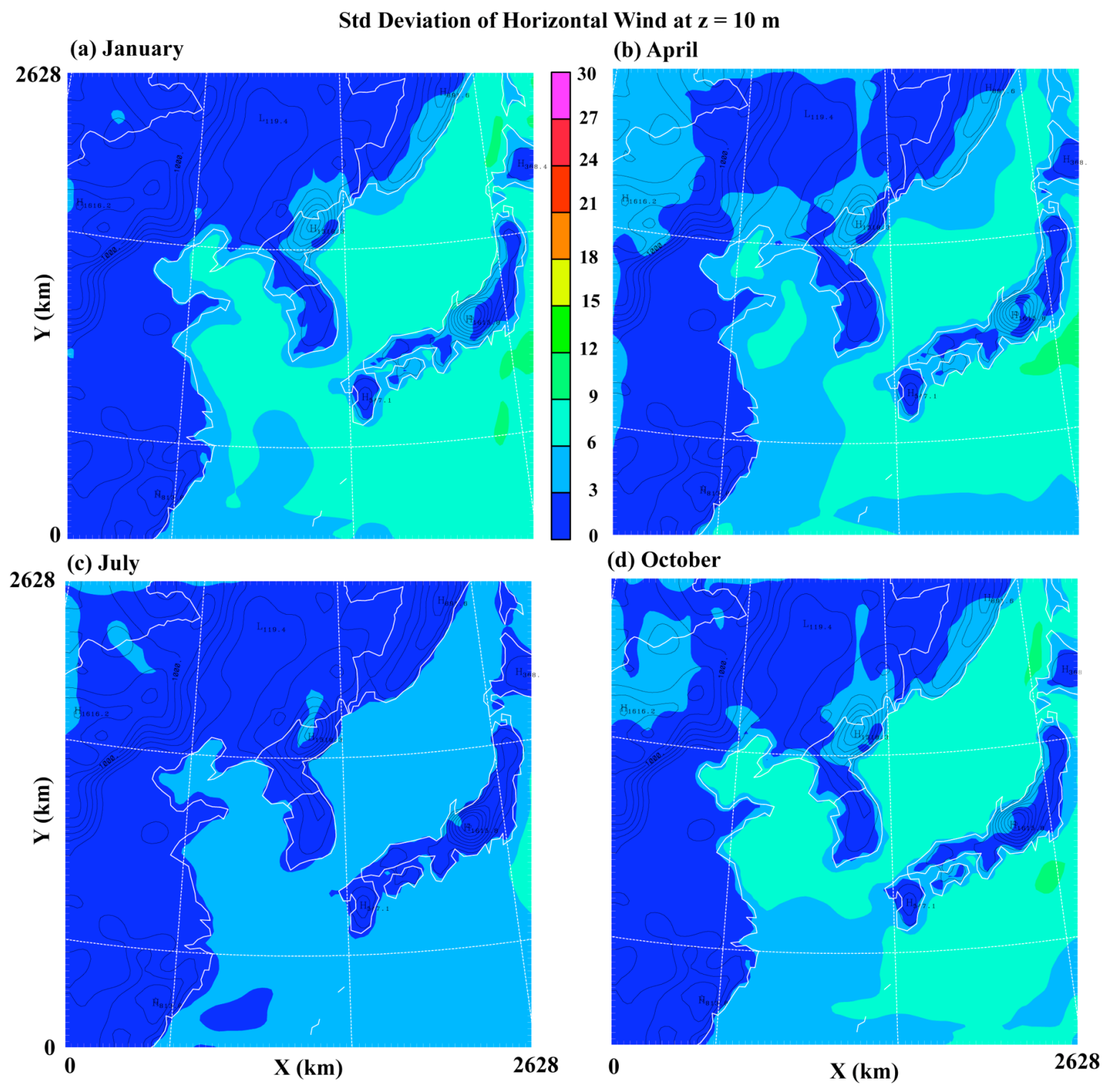

Fig. 11. Same as Fig. 7, except for the standard deviations of horizontal winds at $10 \mathrm{~m}$ altitude. 


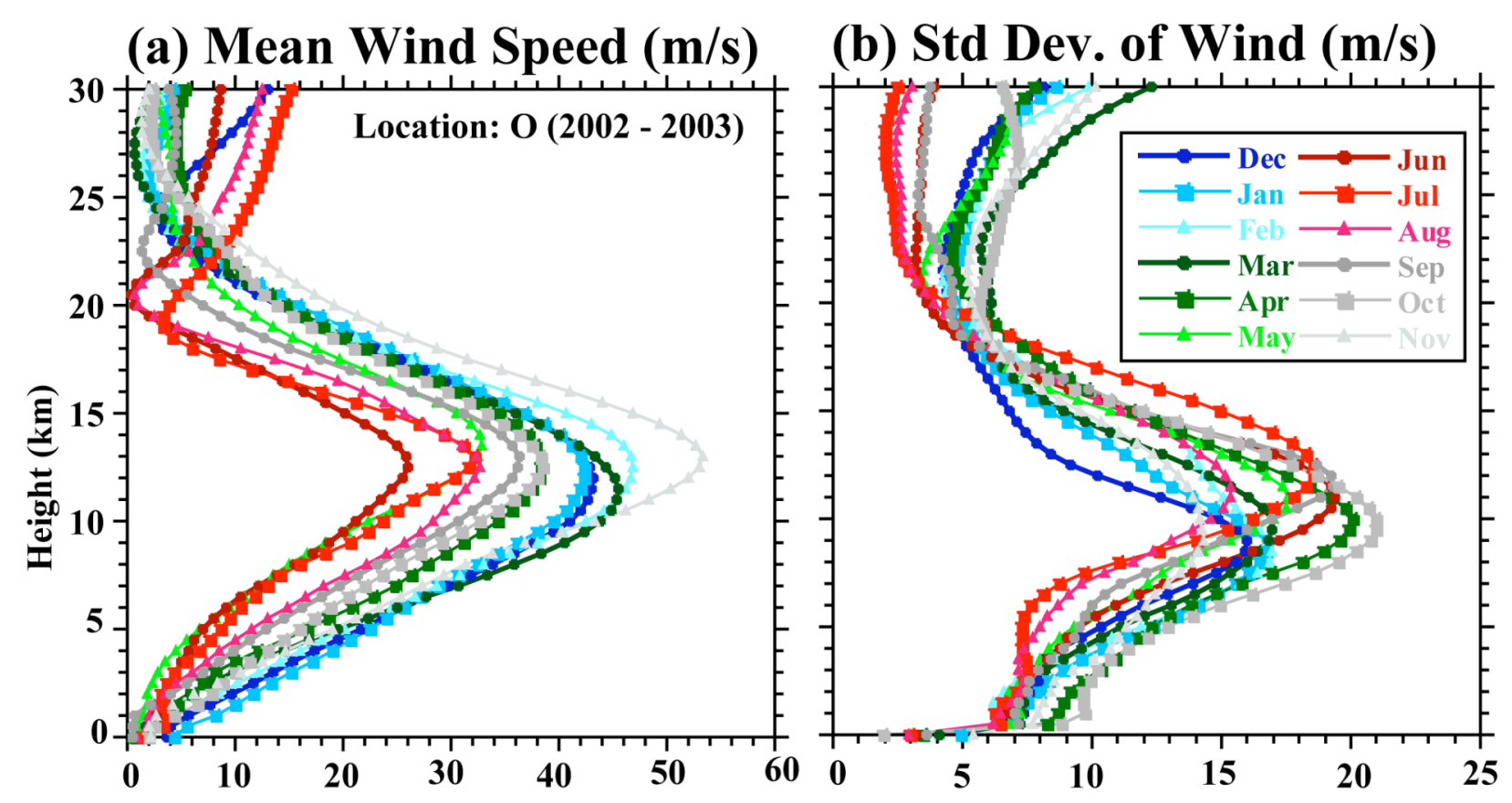

Fig. 12. The vertical profiles of (a) monthly means of horizontal winds, and (b) standard deviations of horizontal winds with respect to the monthly mean at the central part of the Korean peninsula from December 2002 to November 2003. 
Time Series of 10-m Meridional Wind and 2-m Temperature
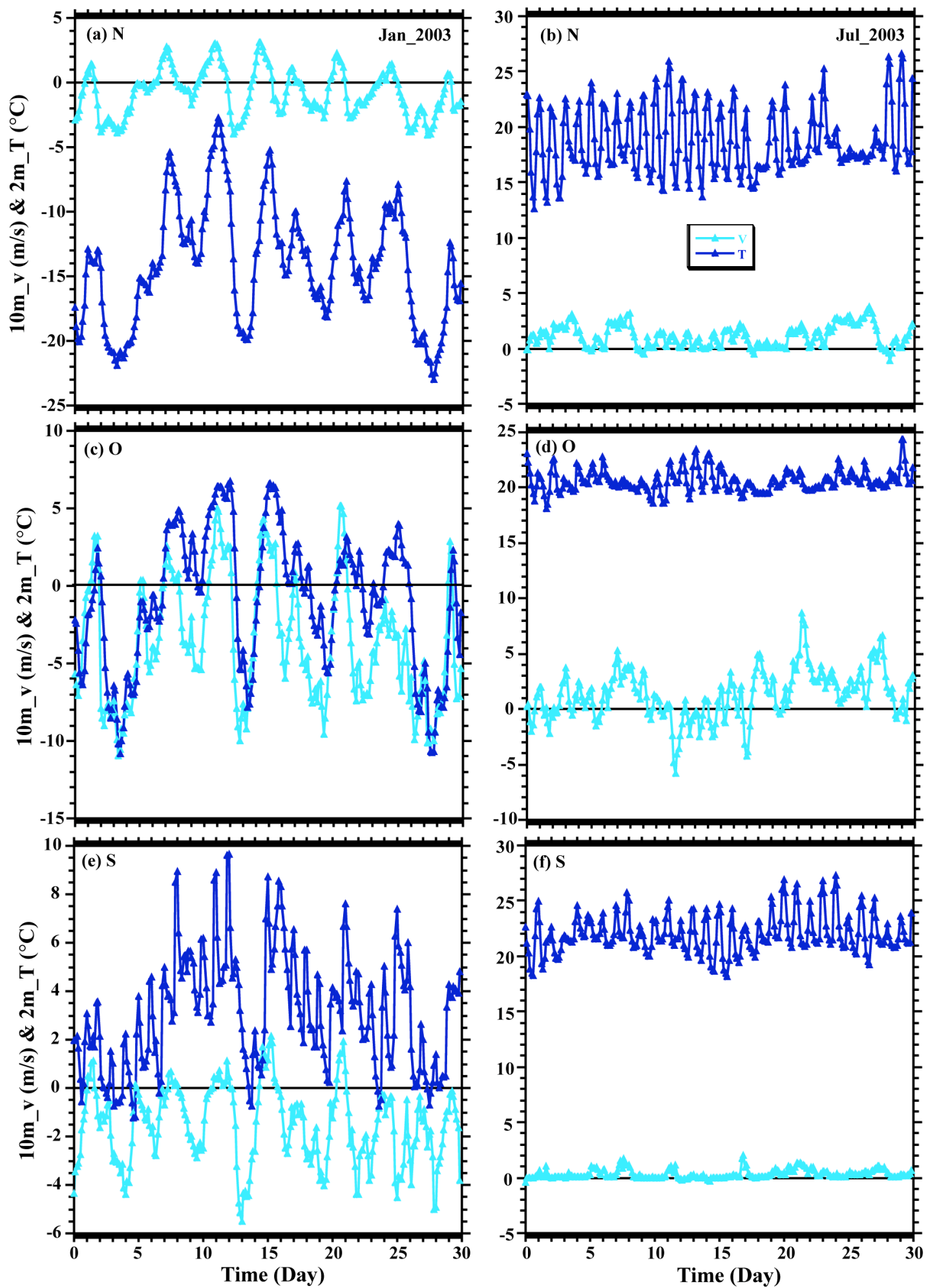

Fig. 13. Time series of 10-m meridional wind and 2-m temperature forecasts from the coarse resolution simulations at the locations of point $\mathrm{N}, \mathrm{O}$, and $\mathrm{S}$ (upper, middle, and lower panels) for January (left panels) and July (right panels) 2003. 


\section{0m U nad V Wind (30 Days)}

(a) January: 3 PM

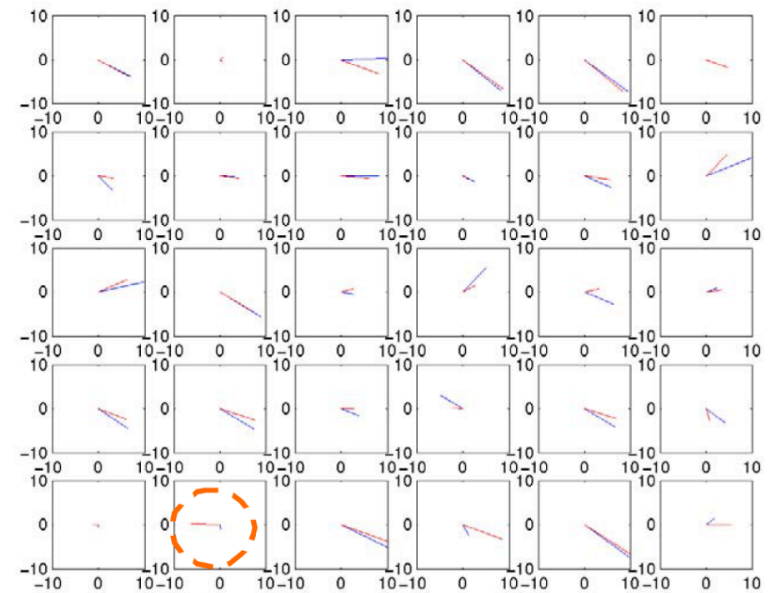

(c) July: 3 PM

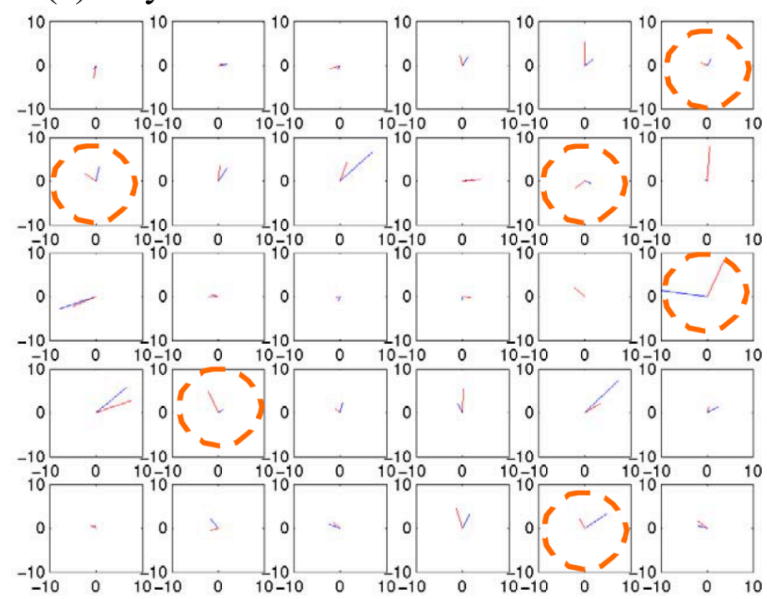

Coarse, Long-range in Blue (b) January: 3 AM

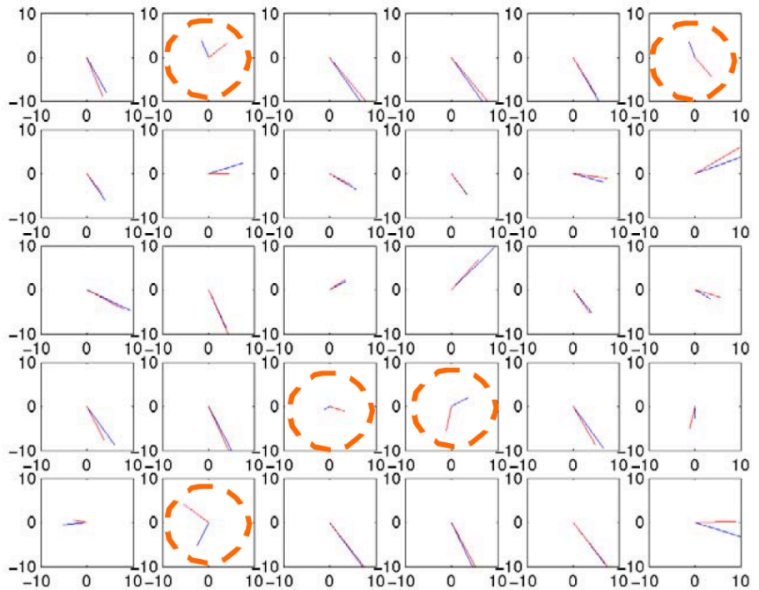

(d) July: 3 AM

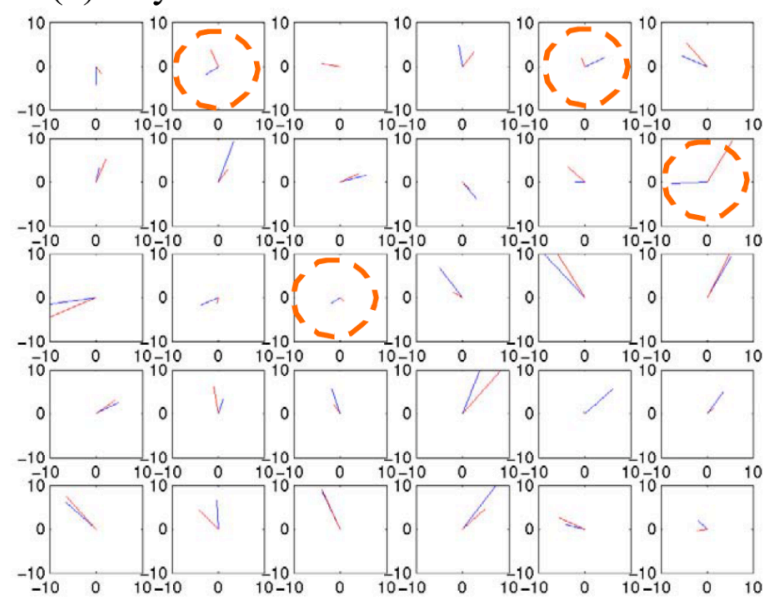

Fine, Daily in Red

Fig. 14. Daily wind comparison between long-range, coarse-resolution and short-range, fine-resolution simulations for January (upper panels) and July (lower panels) 2003. Left panels are for the forecast at 3 PM (local time), and right panels for 3 AM. The red dashed circles mark the time with the wind direction forecasts differ by more than 30 degrees. 

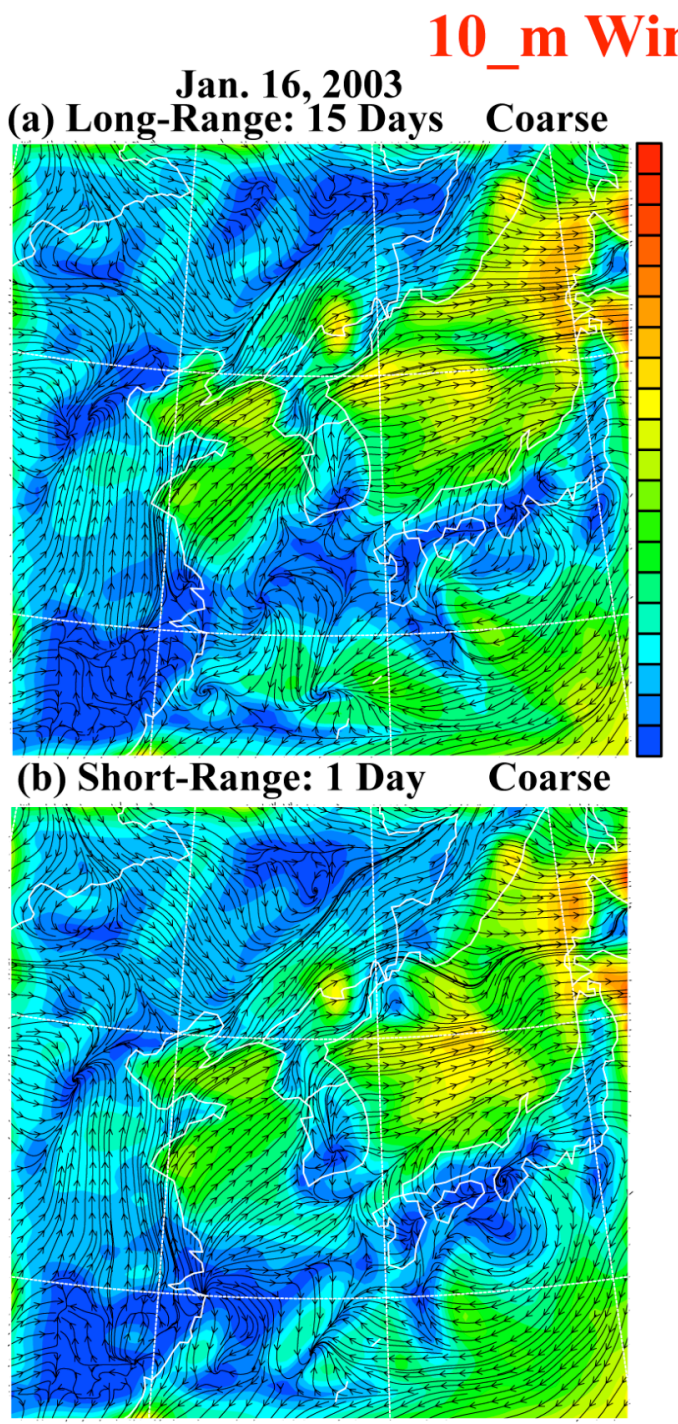

\section{(c) Short-Range: 1 Day Fine}
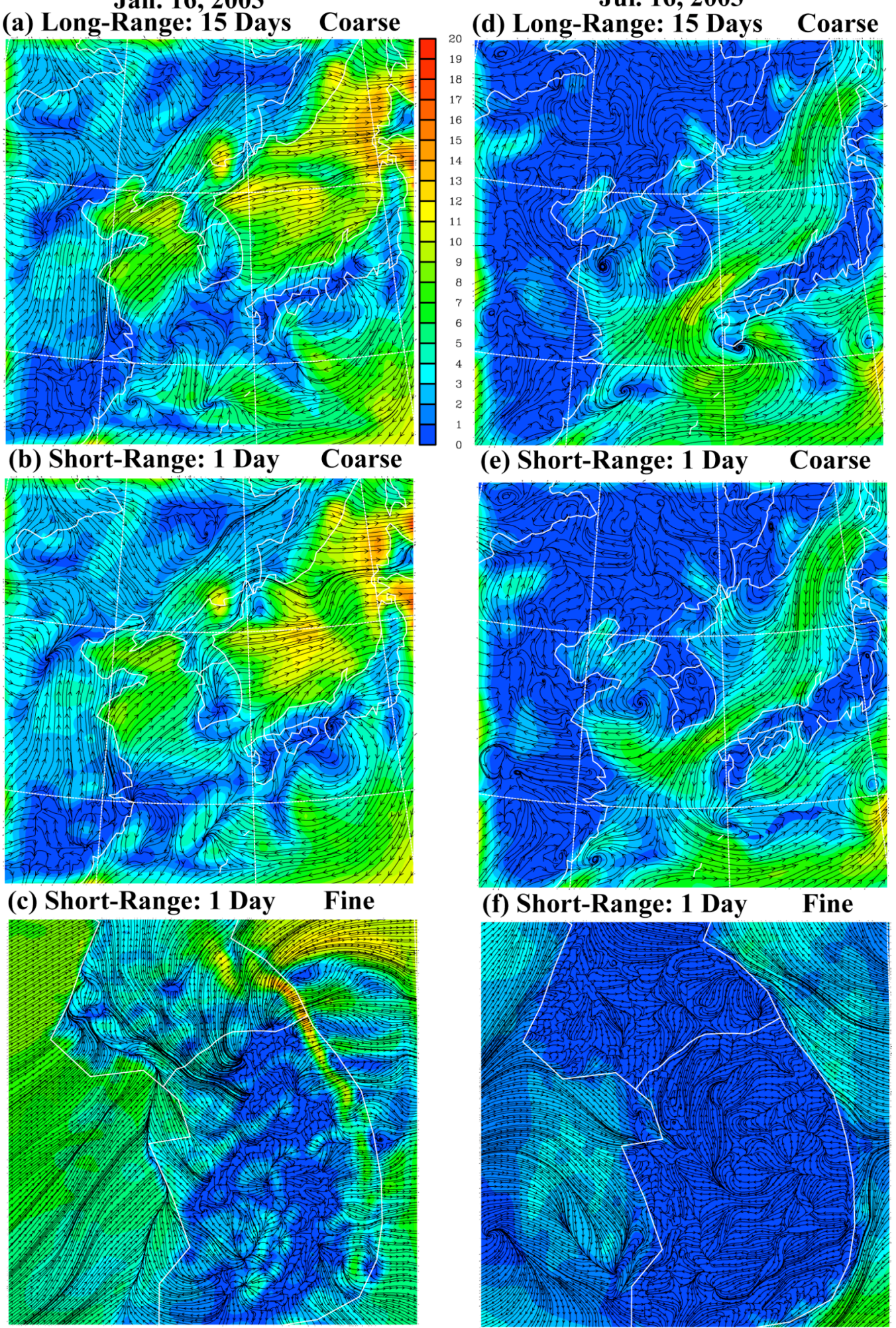

Fig. 15. Horizontal cross-sections of 10-m wind forecasts from long-range coarse- (upper panels), short-range coarse- (middle panels), and short-range fine-resolution (lower panels) simulations valid at 00 GMT January 16 (left panels), and July 16 (right panels) 2003. 

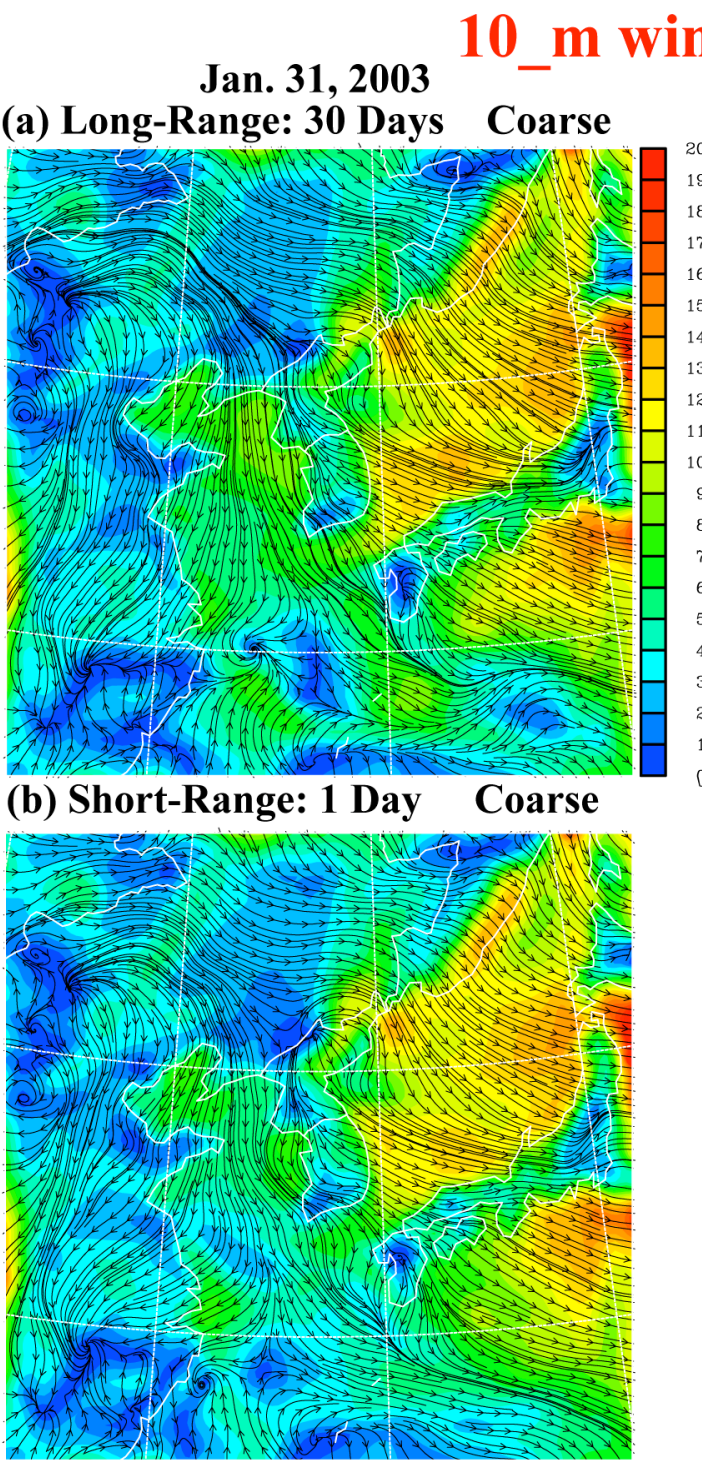

\section{(c) Short-Range: 1 Day Fine}
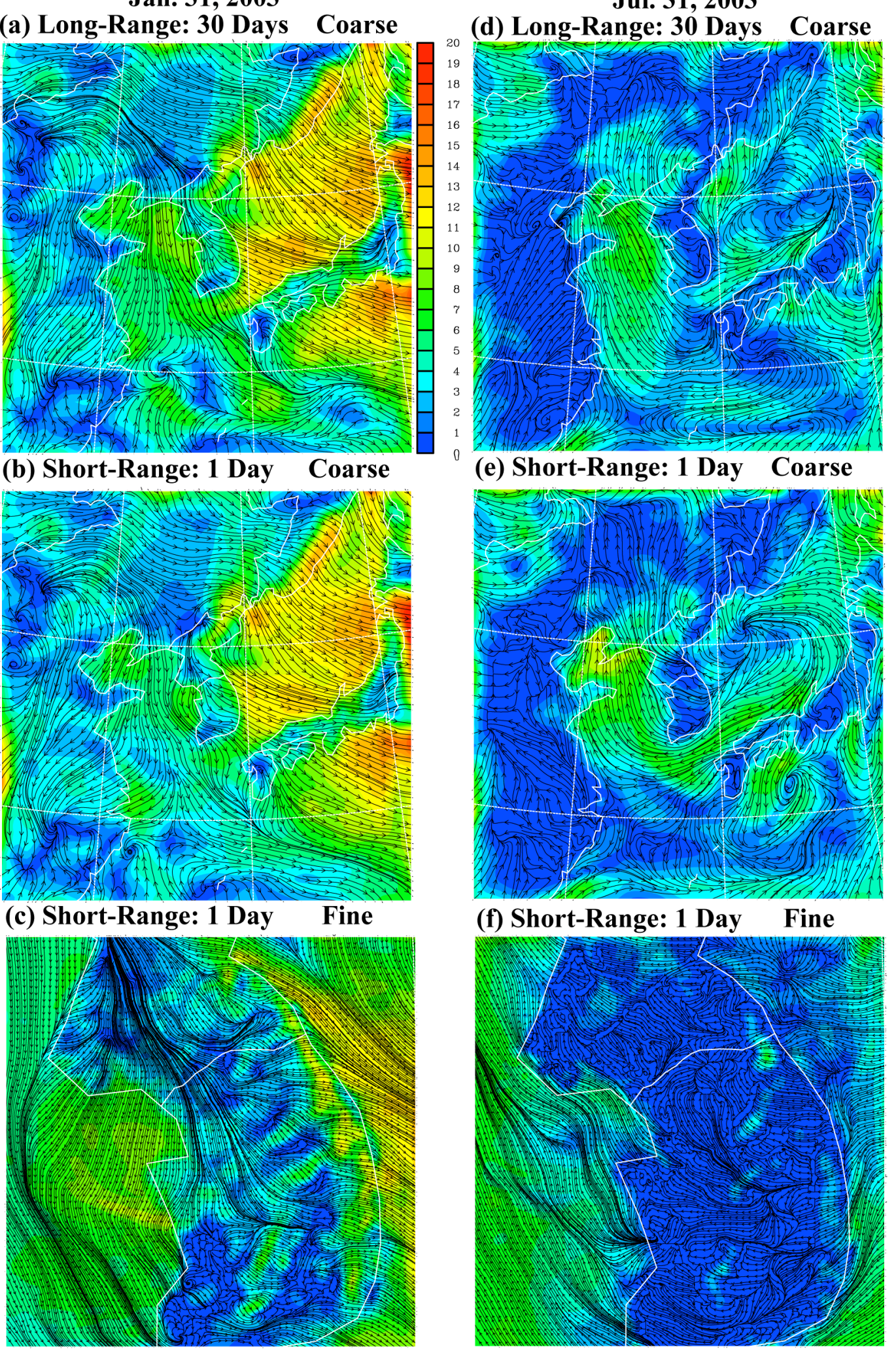

\section{(f) Short-Range: 1 Day Fine}

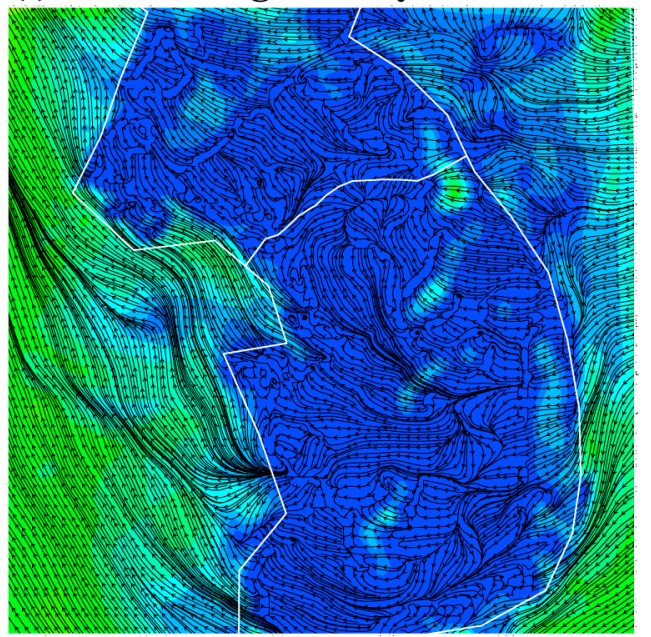

Fig. 16. Same as Fig. 15, except for the valid time at 00 GMT January and July 31, 2003. 


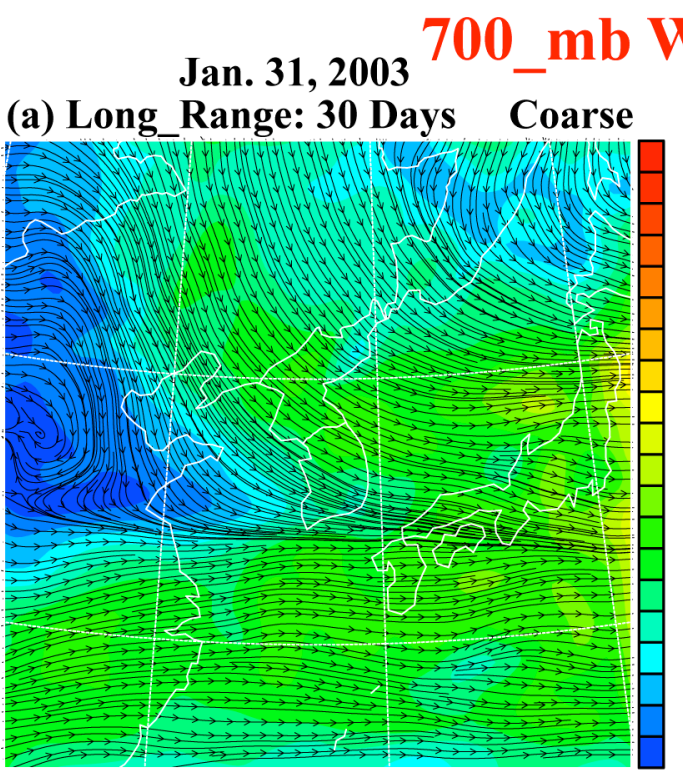

(b) Short_Range: 1 Day

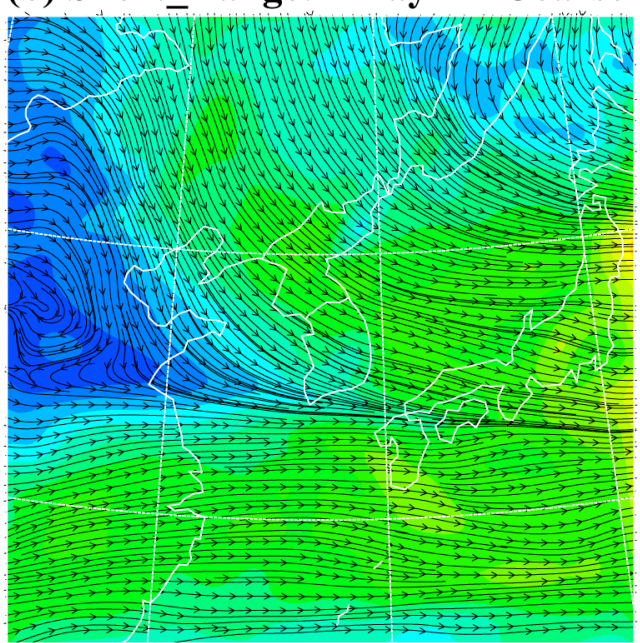

(c) Short_Range: 1 Day

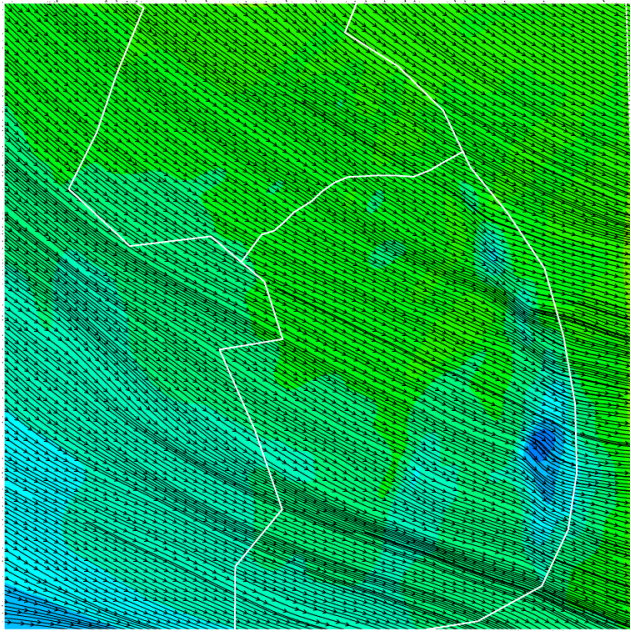

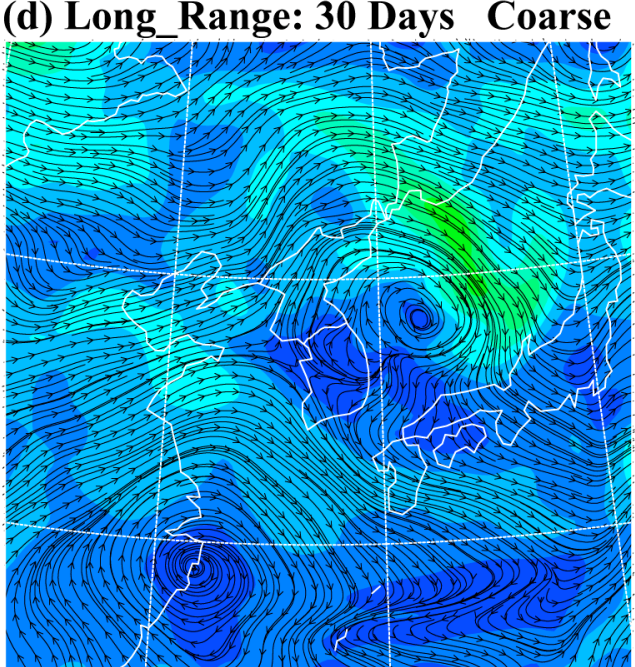

(e) Short_Range: 1 Day Coarse
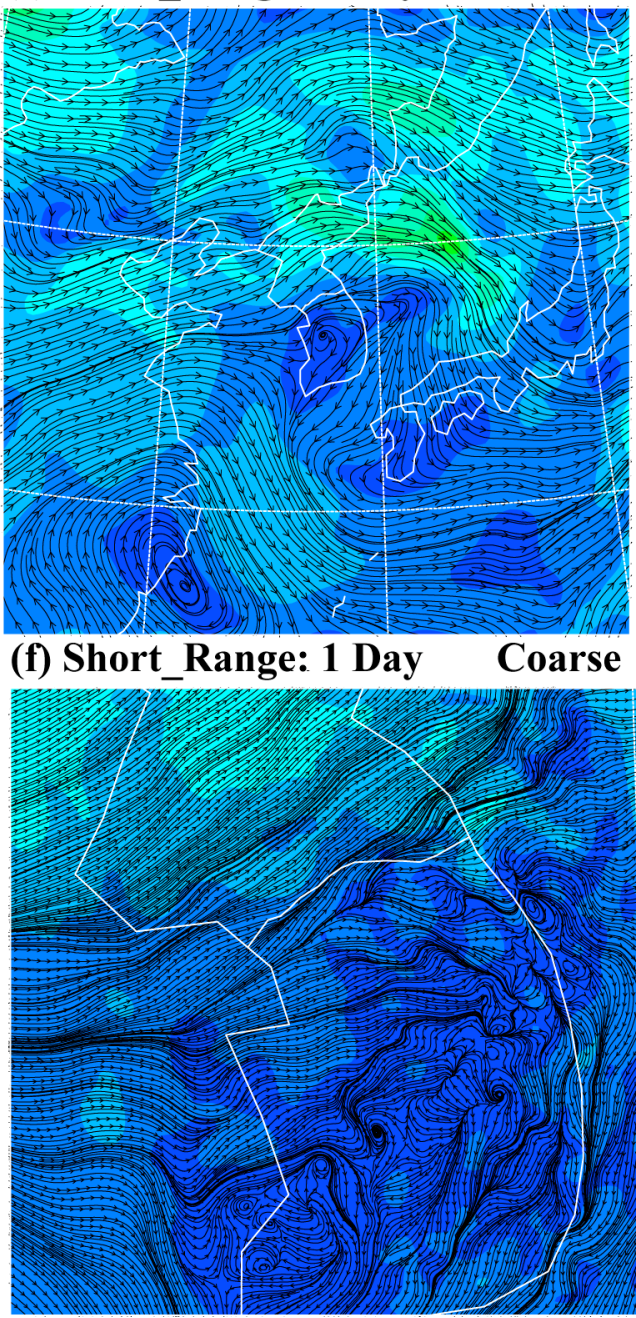

Fig. 17. Same as Fig. 15, except for the forecasts at $700 \mathrm{mb}(\sim 3 \mathrm{~km})$. 


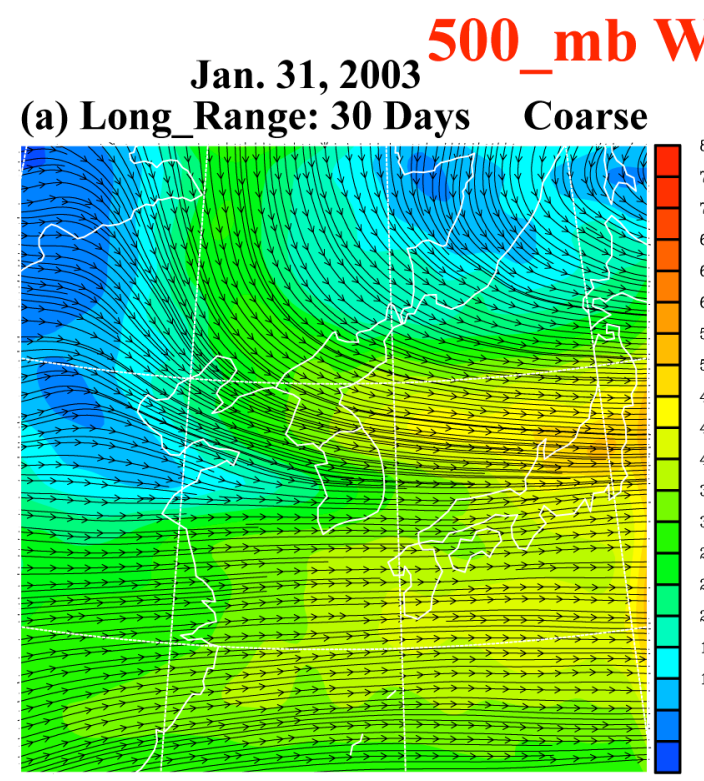

(b) Short_Range: 1 Day Coarse

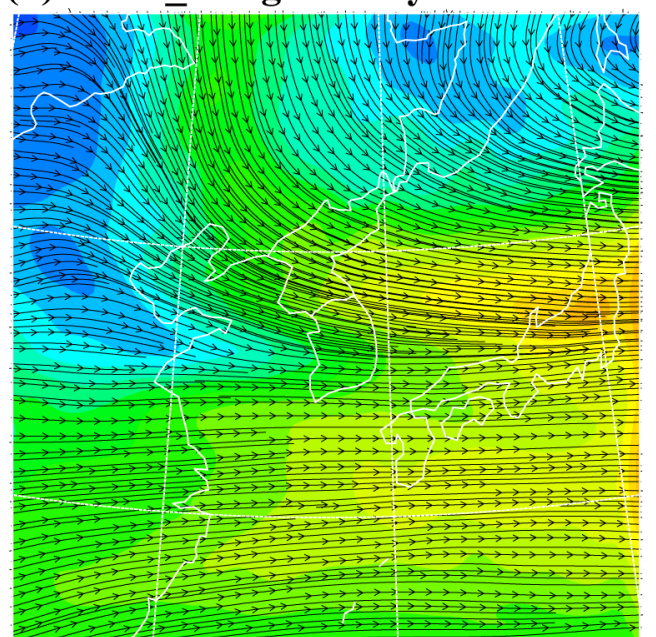

(c) Short Range: 1 Day

Fine
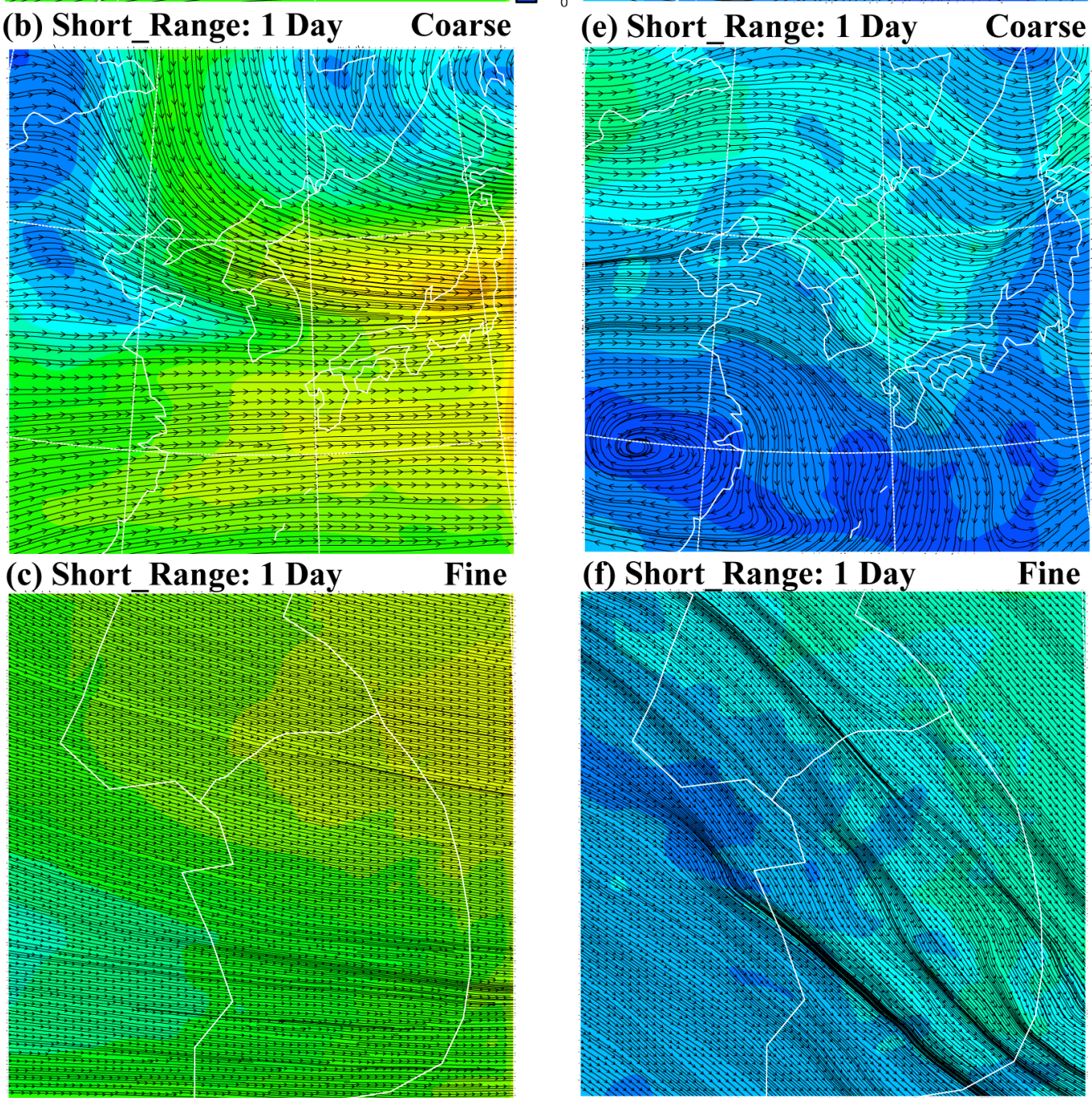

(d) Long_Range: 30 Days Coarse

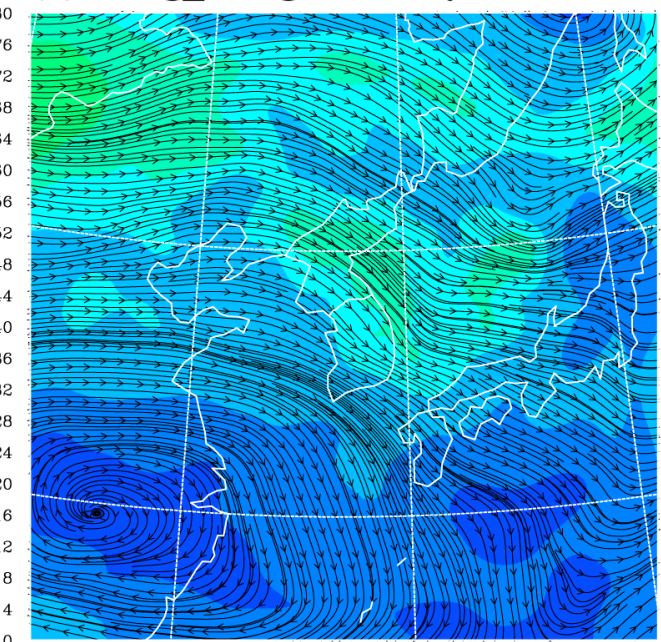

(f) Short Range: 1 Day Fine

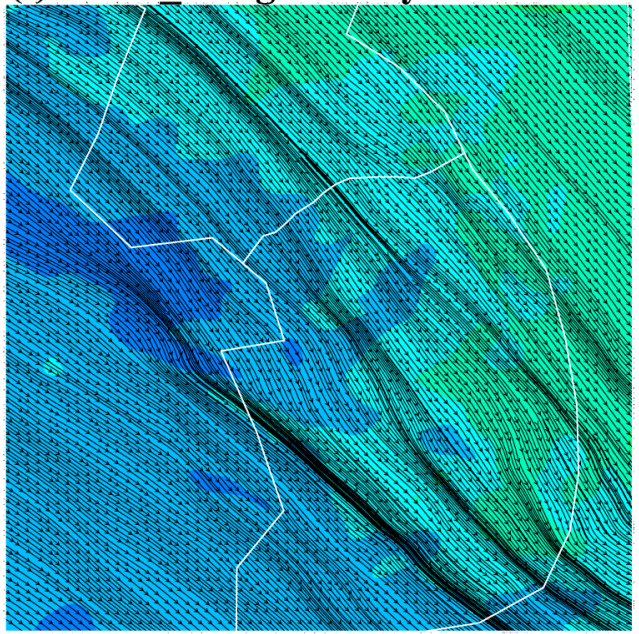

Fig. 18. Same as Fig. 15, except for the forecasts at $500 \mathrm{mb}(\sim 5 \mathrm{~km})$. 
Monthly Mean of Horizontal Wind $(\mathrm{m} / \mathrm{s})$ : Short-Range FCST_n3 $(\Delta x=4 \mathrm{~km})$
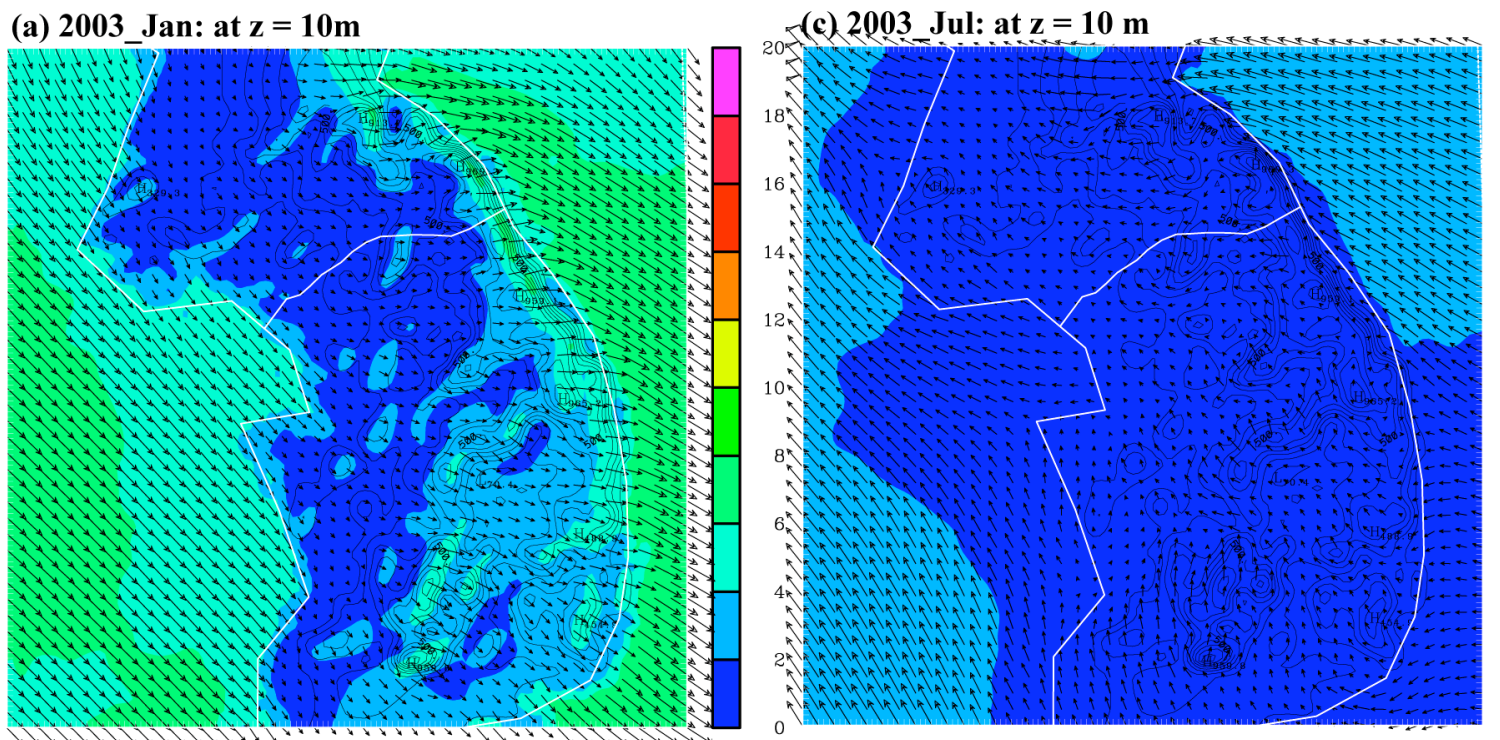

(b) 2003_Jan: at $\mathrm{z}=3.15 \mathrm{~km}$

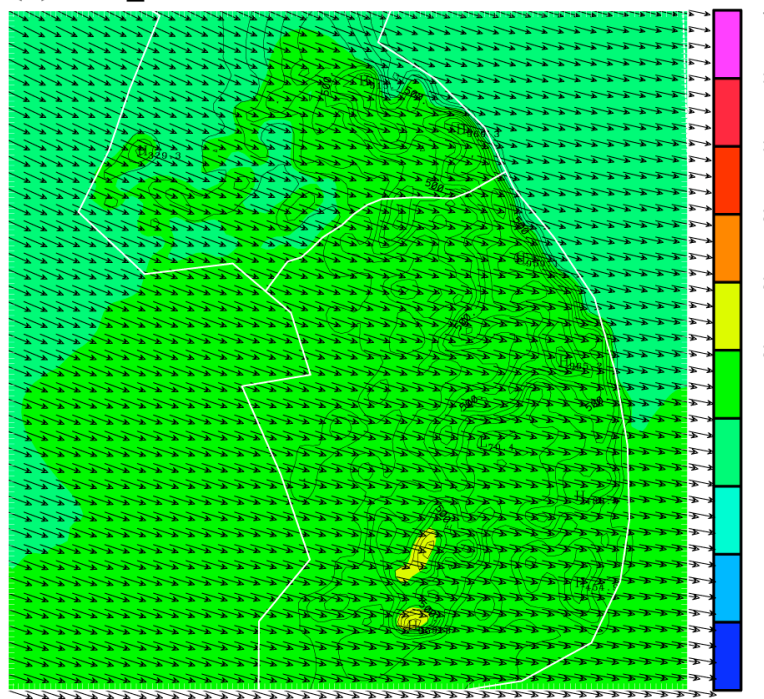

(d) 2003_Jul: at $\mathrm{z}=3.15 \mathrm{~km}$

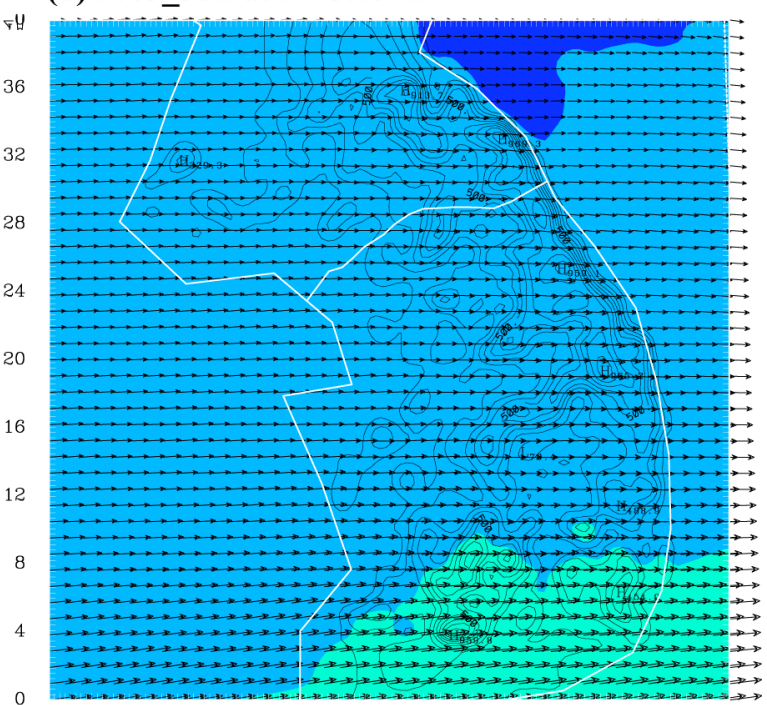

Fig. 19. Horizontal cross-sections of monthly forecast mean winds from short-range fineresolution simulations at 10-m (upper panels), and $3.15 \mathrm{~km}$ (lower panels) altitude. Left panels are for January, 2003, and right panels for July, 2003. 


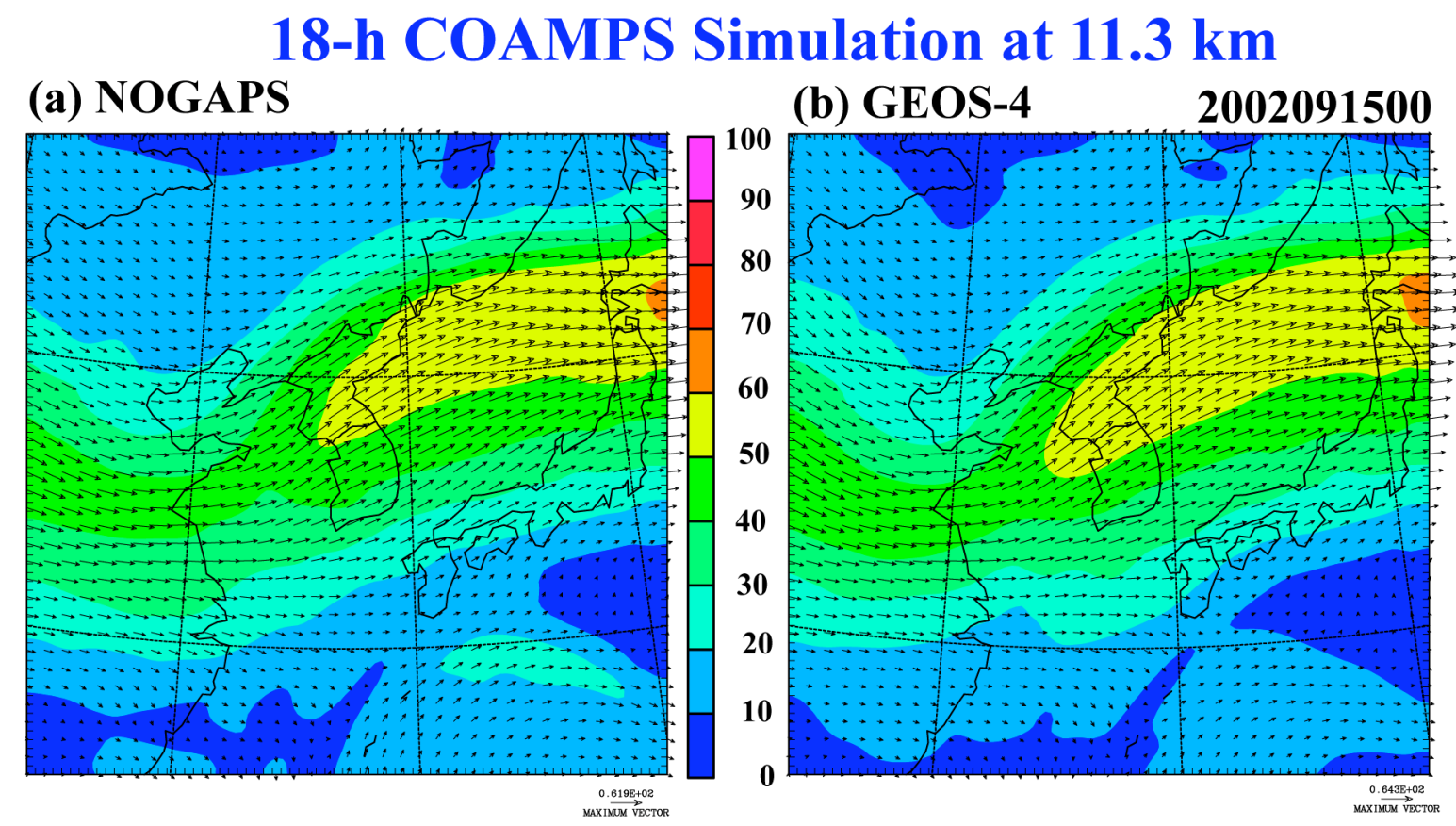

18-h COAMPS Simulation at $1.4 \mathrm{~km}$

(c) NOGAPS

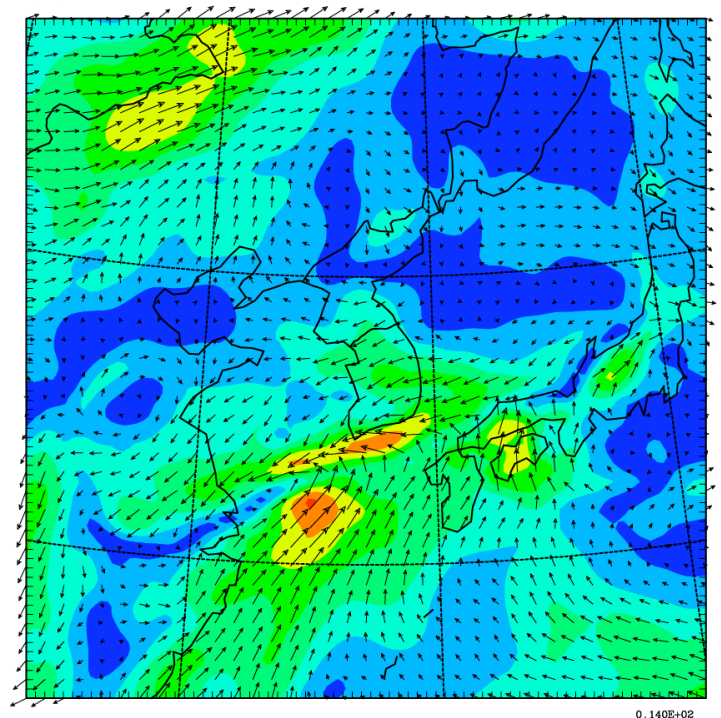

(d) GEOS-4

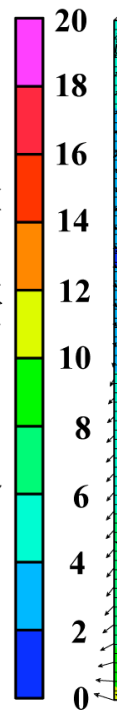

2002091500

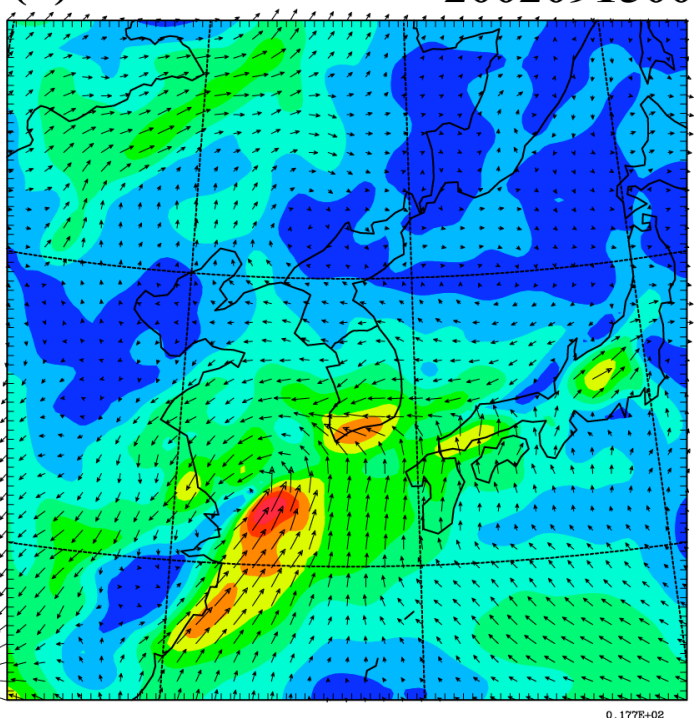

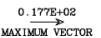

Fig. 20. Benchmark comparisons of short-range, coarse-resolution simulations using the analysis data from NRL NOGAPS (left panels), and NASA GEOS-4 (right panels) at $11.3 \mathrm{~km}$ (upper panels) and $1.4 \mathrm{~km}$ (lower panels) altitude. 
Horizontal Wind $(\mathrm{m} / \mathrm{s})$ at 00Z Sep. 16, 2002

$200209150024 h$ forecast
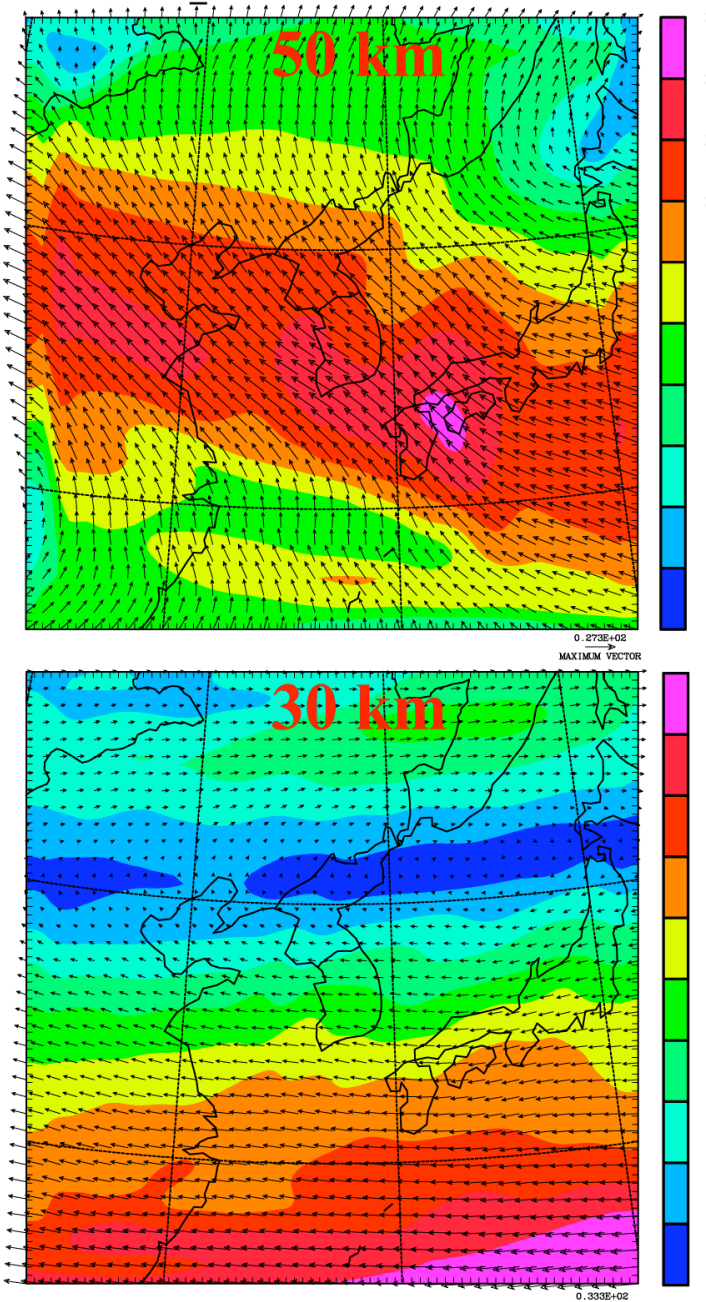

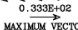

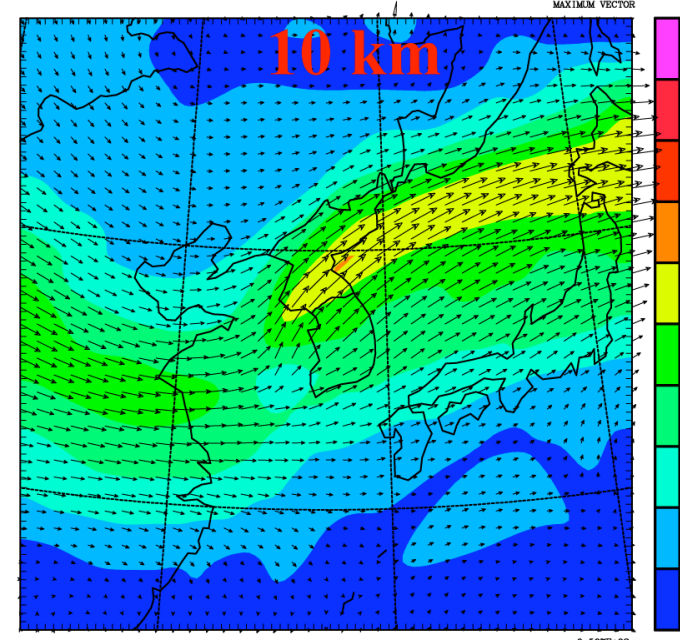

24-h Forecast

\section{0 oh analysis}
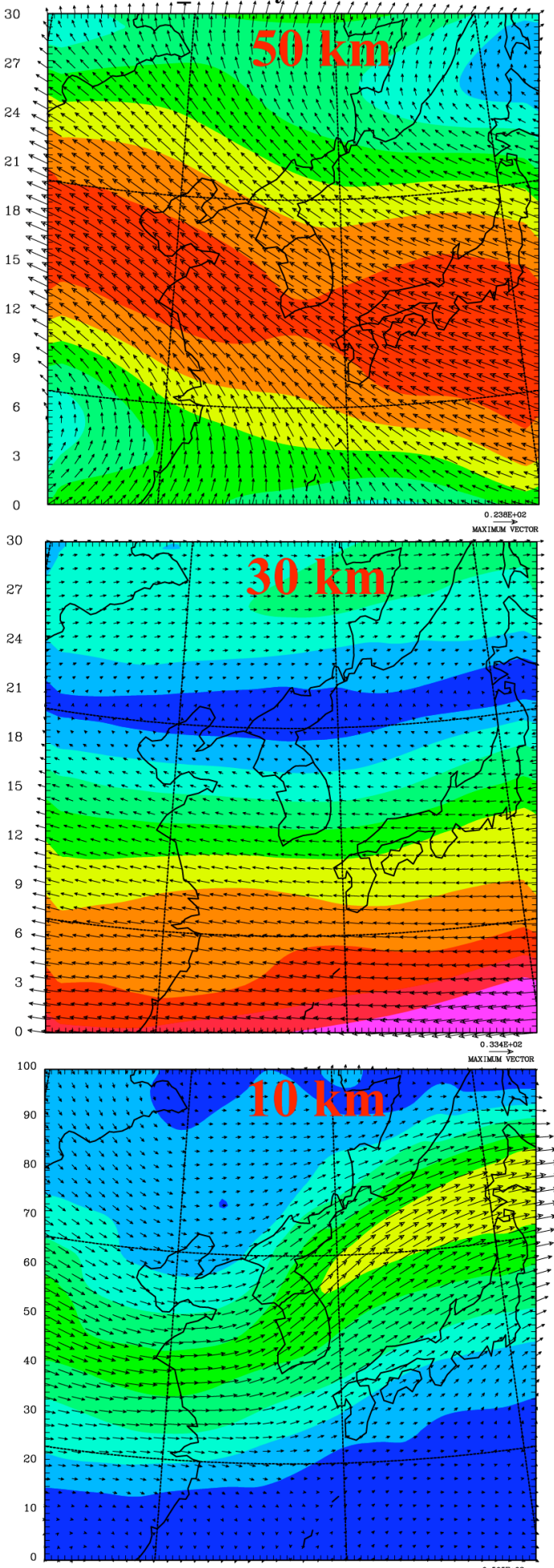

Analysis

axinexs

Fig. 21. Horizontal cross-sections of winds at $50 \mathrm{~km}$ (upper panels), $30 \mathrm{~km}$ (middle panels), and $10 \mathrm{~km}$ (lower panels) altitude for 24-hour forecast (left panels), 
and corresponding analysis data (right panels) at 00 GMT September 16, 2002. 